\title{
Synaptic Regulation by OPRM1 Variants in Reward Neurocircuitry
}

\author{
Dina Popova, ${ }^{1,2}$ Nidhi Desai, ${ }^{1,2}$ Julie A. Blendy, ${ }^{3}$ and $\$ Zhiping P. Pang ${ }^{1,2}$ \\ ${ }^{1}$ Child Health Institute of New Jersey, ${ }^{2}$ Department of Neuroscience and Cell Biology, Rutgers Robert Wood Johnson Medical School, New Brunswick, \\ New Jersey 08901, and ${ }^{3}$ Department of Systems Pharmacology and Translational Therapeutics, Perelman School of Medicine, University of Pennsylvania, \\ Philadelphia, Pennsylvania 19104
}

Mu-opioid receptors (MORs) are the primary site of action of opioid drugs, both licit and illicit. Susceptibility to opioid addiction is associated with variants in the gene encoding the MOR, OPRM1. Varying with ethnicity, $\sim 25 \%$ of humans carry a single nucleotide polymorphism (SNP) in OPRM1 (A118G). This SNP produces a nonsynonymous amino acid substitution, replacing asparagine (N40) with aspartate (D40), and has been linked with an increased risk for drug addiction. While a murine model of human OPRM1 A118G (A112G in mouse) recapitulates most of the phenotypes reported in humans, the neuronal mechanisms underlying these phenotypes remain elusive. Here, we investigated the impact of A118G on opioid regulation of synaptic transmission in mesolimbic VTA dopaminergic neurons. Using electrophysiology, we showed that both inhibitory and excitatory inputs to VTA dopaminergic neurons projecting to the NAc medial shell were suppressed by the MOR agonists DAMGO and morphine, which caused a shift in the excitatory/inhibitory balance and an increased action potential firing rate. Mice carrying the 112G/G allele exhibited lower sensitivity to DAMG0 and morphine compared with major allele carriers (112A/A). Paradoxically, DAMG0 produced facilitatory effects on mEPSCs, which were mediated by presynaptic $\mathrm{GABA}_{\mathrm{B}}$ receptors. However, this was only prominent in homozygous major allele carriers, which could explain a stronger shift in action potential firing in 112A/A mice. This study provides a better understanding on the neurobiological mechanisms that may underlie risk of addiction development in carriers of the A118G SNP in OPRM1.

Key words: MOR; opioid dependence; SNP; VTA

\section{Significance Statement}

The pandemic of opioid drug abuse is associated with many socioeconomic burdens. The primary brain target of opioid drugs is the $\mu$-opioid receptor (MOR), encoded by the OPRM1 gene, which is highly polymorphic in humans. Using a mouse model of the human OPRM1 A118G single nucleotide polymorphism (SNP) (A112G in mice), we demonstrated that MOR and GABA signaling coordinate in regulating mesolimbic dopamine neuronal firing via presynaptic regulation. The A118G SNP affects MOR-mediated suppression of GABA and glutamate release, showing weaker efficacy of synaptic regulation by MORs. These results may shed light on whether MOR SNPs need to be considered for devising effective therapeutic interventions.

\section{Introduction}

Opioid addiction is a chronic, progressive disorder that in part underlies the current epidemic of deaths due to overdose in the
United States. Susceptibility to opioid addiction has been associated with mu- opioid receptor (MOR) gene (OPRM1) variants (Lötsch and Geisslinger, 2005). Of these, A118G (rs1799971) is one of the most prominent nonsynonymous single nucleotide polymorphisms (SNPs), which has been found to have the highest overall allelic frequency of all of the OPRM1 coding region variants (Bond et al., 1998). The A118G SNP in OPRM1 replaces asparagine (N40) with aspartate (D40) in the MOR, and N40D variants are linked to both drug and alcohol use disorders in several model systems. However, the results are inconsistent, which may be explained by variations in the genetic backgrounds between different ethnic groups (Ray and Hutchison, 2004; 
Ehlers et al., 2008; Miranda et al., 2010; Koller et al., 2012; Enoch, 2013). A more recent epidemiological study, using a large subject pool, also argued against the link between A118G and alcohol use (Sloan et al., 2018). However, in these clinical studies, a host of potential covariates of addiction severity makes it impossible to isolate the effects of this genotype alone. Therefore, the Oprm1 A112G mouse model was developed to mimic the human OPRM1 A118G SNP by generating mice with the equivalent mutation through gene targeting (Mague et al., 2009). Remarkably, these mice reproduce most of the phenotypes reported for the human OPRM1 SNP, including altered morphine-mediated antinociception, the rewarding properties of morphine, and the response to naloxone-precipitated morphine withdrawal. In addition, it was found that the Oprm1 A112G SNP alters MOR N-linked glycosylation and protein stability (Huang et al., 2012; Wang et al., 2012), affects heroin self-administration (Zhang et al., 2015), increases sociability and dominance, and confers resilience to social defeat (Briand et al., 2015). However, the functional role of A118G in reward neurocircuitry remains elusive.

Opioids mediate their reinforcing properties by acting on the mesolimbic dopaminergic (DA) system (Di Chiara and Imperato, 1988). Although it was demonstrated that opioids stimulate DA release through disinhibition of DA neurons, via suppression of VTA inhibitory neurons (Johnson and North, 1992; Matsui et al., 2014), it was also reported that DA neurons in the VTA receive inhibitory inputs from various brain regions (Matsui et al., 2014). In addition, $\mathrm{GABA}_{\mathrm{A}} \mathrm{R}$-mediated synaptic transmission can be inhibited by MOR activation (Johnson and North, 1992; Bonci and Williams, 1997; Chieng et al., 2011; Matsui et al., 2014). Glutamate release to VTA neurons has also been reported to be regulated by the MOR (Bonci and Malenka, 1999; Chen et al., 2015). Moreover, due to the high heterogeneity of VTA neurocircuitry, overall responses of DA neurons to opioids are diverse (Margolis et al., 2014).

To reveal the functional impact of the Oprm1 SNP A112G on synaptic transmission in reward circuitry, we used slice physiology to investigate how this SNP influences VTA DA neuronal function. We examined a specific population of VTA DA neurons that project to the NAc medial shell (mAcbSh), which is involved in motivation for both natural rewards and drugs of abuse (Kauer and Malenka, 2007; Lammel et al., 2011). We found that the Oprm1 A112G SNP has a profound influence on the regulation of opioid signaling in these VTA-to-mAcbSh-projecting neurons. DAMGO significantly suppressed both inhibitory and excitatory neurotransmitter release onto VTA DA-to-mAcbSh neurons in $112 \mathrm{~A} / \mathrm{A}$, but not in $112 \mathrm{G} / \mathrm{G}$ mice, indicating differential expression or signaling of the MOR. As a consequence, the functional output for MOR regulation of DA neuronal firing is different between the A- and G-allele carriers, and this will likely impact differential behavioral outcomes for drugs of abuse.

\section{Materials and Methods}

Animals. All animal experiments were done in accordance with the Rutgers Robert Wood Johnson Medical School Institutional Animal Care and Use Committee. To specifically target the VTA DA neurons, Oprm1 A112G mice (Mague et al., 2009) were crossed with DAT-IRES-Cre mice (The Jackson Laboratory, stock \#006660) (Zhuang et al., 2005). Animals were group housed and kept under a $12 \mathrm{~h}$ light/dark cycle, with food and water available ad libitum. Only adult male mice between 6 and 10 weeks old were used in this study.

Locomotor behavior. Locomotor activity was monitored with the SmartCage system (AfaSci) and analyzed with CageCenter software (AfaSci). On days 1-3, animals of both genotypes were tested for baseline response with saline injections, and their activity was monitored for 40 min. On days 4-8, all animals received morphine injections $(10 \mathrm{mg} / \mathrm{kg}$, i.p.), and their locomotor activity was measured for $40 \mathrm{~min}$ following the injection.

Stereotactic surgery. Stereotactic injections were performed under isoflurane anesthesia (5\% isoflurane for induction and 1.5\%-2\% during the surgery) using a stereotactic instrument (M1900, Kopf Instruments). For $\mathrm{mAcbSh}$-projecting VTA neuronal labeling, mice were injected bilaterally with $0.25 \mu \mathrm{l}$ of red fluorescent RetroBeads (Lumafluor) using the following coordinates: anteroposterior $1.8 \mathrm{~mm}$, mediolateral $\pm 0.6 \mathrm{~mm}$, dorsoventral $-4.1 \mathrm{~mm}$. For labeling of DA VTA neurons, we used AAVEF1a-DIO-EYFP virus (Vector Core at the University of North Carolina). We delivered $0.6-1 \mu \mathrm{l}$ of virus bilaterally using the following coordinates: anteroposterior $-3.5 \mathrm{~mm}$, mediolateral $\pm 0.3 \mathrm{~mm}$, dorsoventral $-4.2 \mathrm{~mm}$. Electrophysiology was performed $14-21 \mathrm{~d}$ after injection. Analyses of the injection sites were routinely performed, and animals with misplaced injections were discarded from further experiments.

Slice electrophysiology. Mice were deeply anesthetized with Euthasol and transcardially perfused with ice-cold oxygenated $\left(95 \% \mathrm{O}_{2} / 5 \% \mathrm{CO}_{2}\right)$ aCSF containing the following (in $\mathrm{mM}$ ): $125 \mathrm{NaCl}, 2.5 \mathrm{KCl}, 1.25$ $\mathrm{NaH}_{2} \mathrm{PO}_{4}, 25 \mathrm{NaHCO}_{3}, 2.5$ glucose, 50 sucrose, $0.625 \mathrm{CaCl}_{2}$, and 1.2 $\mathrm{MgCl}_{2}$, and coronal midbrain slices $(300 \mu \mathrm{m})$ containing VTA region were cut. Then slices recovered for $30 \mathrm{~min}$ at $30^{\circ} \mathrm{C}$ in oxygenated $(95 \%$ $\mathrm{O}_{2} / 5 \% \mathrm{CO}_{2}$ ) aCSF containing the following (in $\mathrm{mm}$ ): $125 \mathrm{NaCl}, 2.5 \mathrm{KCl}$, $1.25 \mathrm{NaH}_{2} \mathrm{PO}_{4}, 25 \mathrm{NaHCO}_{3}, 2.5$ glucose, 22.5 sucrose, $2.5 \mathrm{CaCl}_{2}$, and 1.2 $\mathrm{MgCl}_{2}$. Electrophysiological recordings were performed in the same solution with perfusion rate of $2 \mathrm{ml}$ per min at $37^{\circ} \mathrm{C}$. All recordings were performed only with neurons containing both EYFP and red RetroBeads. Patch pipettes $(4-6 \mathrm{~m} \Omega$ ) were pulled from borosilicate glass. For wholecell voltage-clamp recordings, a cesium-based internal solution was used, containing the following (in $\mathrm{mm}$ ): $40 \mathrm{CsCl}, 90 \mathrm{~K}$-gluconate, $10 \mathrm{HEPES}$, 0.05 EGTA, $1.8 \mathrm{NaCl}, 3.5 \mathrm{KCl}, 1.7 \mathrm{MgCl}_{2}$, $2 \mathrm{Mg}$-ATP, $0.4 \mathrm{Na}_{4}$-GTP, and 10 phosphocreatine, $\mathrm{pH}$ 7.2. For whole-cell current-clamp recordings and cell-attached recordings, a potassium-based internal solution was used, containing the following (in $\mathrm{mm}$ ): $126 \mathrm{~K}$-gluconate, $4 \mathrm{KCl}, 10$ HEPES, 0.05 EGTA, $4 \mathrm{Mg}$-ATP, $0.3 \mathrm{Na}_{4}$-GTP, and 10 phosphocreatine, $\mathrm{pH}$ 7.2. Whole-cell patch-clamp recordings were performed using an Axon $700 \mathrm{~B}$ amplifier. Data were filtered at $2 \mathrm{kHz}$, digitized at $10 \mathrm{kHz}$, and collected using Clampex 10.6 (Molecular Devices). To evaluate the effects of MOR-mediated responses 0.1-10 $\mu \mathrm{M}$ DAMGO (Hellobio), $1 \mu \mathrm{M}$ naltrexone (Hellobio), and 0.1-10 $\mu \mathrm{M}$ morphine were used. To record sEPSCs, picrotoxin (50 $\mu \mathrm{M}$, Tocris Bioscience) was added to block $\mathrm{GABA}_{\mathrm{A}} \mathrm{R}$-mediated currents. To record sIPSCs, CNQX (20 $\mu \mathrm{M}$, Enzo Life Science) was added to block glutamate receptor-mediated current responses. To block $\mathrm{GABA}_{\mathrm{B}} \mathrm{R}$-mediated synaptic transmission, CGP 55845 ( $1 \mu \mathrm{M}$, Tocris Bioscience) was used. TTX ( $1 \mu \mathrm{M}$, Enzo Life Science) was used to block action potentials (APs) to isolate mEPSCs and mIPSCs. Electrophysiological data were analyzed using ClampFit 10.6 software.

Immunohistochemistry. Animals were deeply anesthetized with Euthasol and transcardially perfused with PBS, $\mathrm{pH} 7.4$, followed by chilled $4 \%$ PFA in PBS. Brains were removed from the skull after perfusion and postfixed in $4 \%$ PFA overnight at $4^{\circ} \mathrm{C}$. Coronal sections $(50 \mu \mathrm{M})$ were prepared with a vibratome.

Brain slices containing the VTA were incubated in a blocking reagent containing 3\% BSA (Sigma-Aldrich) in PBS with $0.2 \%$ Triton X-100 (Sigma-Aldrich). The following primary antibodies (1:1000 dilution in PBS with $0.2 \%$ Triton $\mathrm{X}-100$, overnight incubation at $4^{\circ} \mathrm{C}$ ) were used: anti-MOR (ab134054, Abcam); anti-vesicular GABA transporter (VGAT, \#131011, SYSY), anti-vesicular glutamate transporter 2 (VGluT2, \#135411, SYSY), and anti-TH (ab1542, Millipore). Sections were then washed in PBS and incubated with the appropriate secondary antibodies (Molecular Probes, Invitrogen) for $1 \mathrm{~h}$ at room temperature. Finally, sections were mounted on slides and covered with FluoroShield mounting media, containing DAPI (Sigma-Aldrich). MOR KO mice (Schuller et al., 1999) were used to validate the specificity of MOR staining. The images were obtained with an LSM 700 confocal microscope (Carl Zeiss) using ZEN software.

Statistical analysis. The effects of MOR agonists (DAMGO or morphine) as well as the $\mathrm{GABA}_{\mathrm{B}} \mathrm{R}$ antagonist were normalized to basal activ- 
A

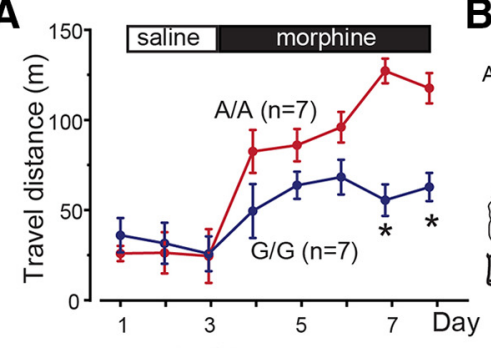

B

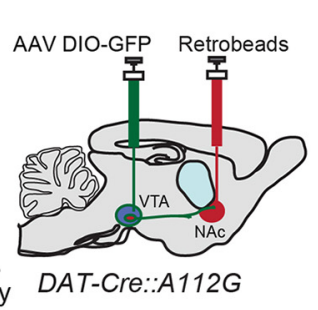

C

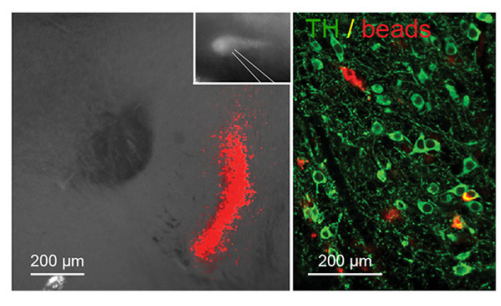

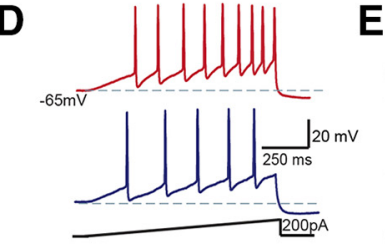

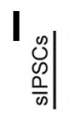

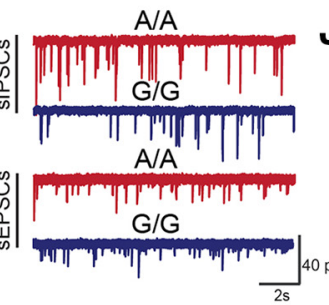

L
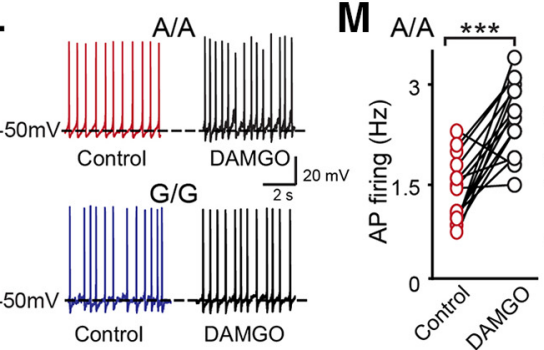

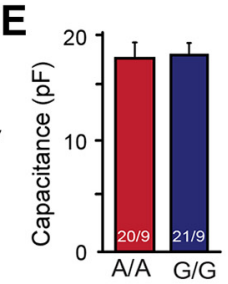

$F$

J

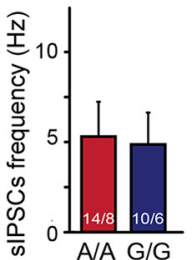

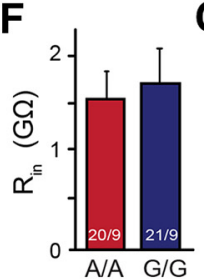

G

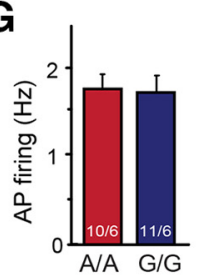

$\mathrm{K}$
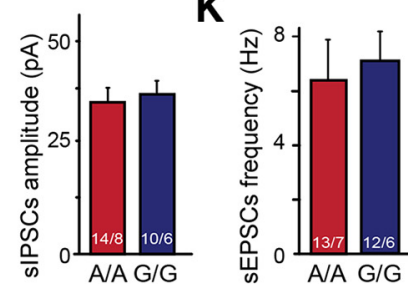

H
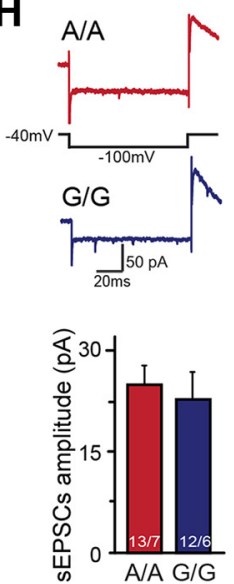

$\mathrm{N}_{\text {G/G }}$

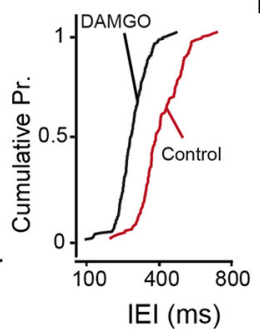

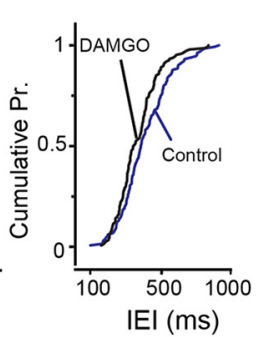

Figure 1. Activation of MORs produces differential effects on locomotion and VTA-to-mAcbSh-projecting DA neurons in Oprm $1112 \mathrm{~A} / \mathrm{A}$ and $112 \mathrm{G} / \mathrm{G}$ mice. A, Locomotor activity measurements of double-transgenic DAT-ires-Cre:A112G mice after repeated morphine administration (one-way ANOVA, $n=7$ for A/A and $n=7$ for G/G mice). B, Schematic showing dual injection of AAV DIO-YFP into VTA and red fluorescent RetroBeads into the mAcbSh. C, Fluorescence image showing representative example of the injection site with red RetroBeads in mAcbSh (left). Right, Retrogradely labeled VTA DA neurons and confocal image showing TH immunostaining. Inset, A whole-cell patched VTA DA neuron. D, Representative traces of elicited APs in VTA-to-mAcbSh-projecting DA neurons in $112 \mathrm{~A} / \mathrm{A}$ and $112 \mathrm{G} / \mathrm{G}$ mice. $\boldsymbol{E}$, Pooled data of capacitance in VTA-to-mAcbSh-projecting DA neurons. $\boldsymbol{F}$, Pooled data of input resistance in VTA-to-mAcbSh-projecting DA neurons. G, Pooled data of sAP firing in VTA-to-mAcbSh-projecting DA neurons. $\boldsymbol{H}$, Representative traces of hyperpolarization pulse-induced current responses in VTA-to-mAcbSh-projecting DA neurons in 112A/A and $112 \mathrm{G} / \mathrm{G}$ mice. Pooled data of sAP firing in VTA-to-mAcbSh-projecting DA neurons. I, Representative traces of sIPSCs and sEPSCs recorded from VTA-to-mAcbSh-projecting DA neurons from 112A/A and $112 \mathrm{G} / \mathrm{G}$ mice. J, Pooled data of sIPSC frequency and amplitude recorded from VTA-to-mAcbSh-projecting DA neurons. $\boldsymbol{K}$, Pooled data of sEPSC frequency and amplitude recorded from VTA-to-mAcbSh-projecting DA neurons. L, Representative traces of sAP firing in VTA-to-mAcbSh-projecting DA neurons in response to MOR agonist DAMGO (1 $\mu \mathrm{M}) . M$, Pooled data of individual DA neuronal responses and cumulative probability plot of AP interevent intervals (IEls) to application of DAMGO in major allele carriers. Left, One-way ANOVA $(p<0.05), n=15 / 7$, cell numbers/mice. Right, KS test $(p<0.001)$. N, Pooled data of individual DA neuronal responses and cumulative probability plot of AP IEls to application of DAMGO in minor allele carriers. Left, One-way ANOVA ( $p<$ $0.05), n=15 / 8$, cell numbers/mice. Right, KS test $(p=0.676)$. Data are mean \pm SEM. Number of neurons/number of animals are indicated in bars. Paired $t$-test was used to evaluate within-genotype differences: ${ }^{*} p<0.05,{ }^{* *} p<0.01,{ }^{* * *} p<0.001$.

ity in the absence of the drugs; that is, drug effects are defined as the relative changes to the baseline (in the absence of drug) values. The effect of drugs before and after the application in the same group of cells were compared using paired $t$ test. On normalized post-treatment data, one-way ANOVA tests were used to evaluate the effects between genotypes. For cumulative probability distribution, Kolmogorov-Smirnov (KS) tests were used to evaluate pretreatment and post-treatment effects. Data were considered statistically significant if $p<0.05$. All data are presented as \pm SEM, and $n$ values indicate the number of cells recorded/animals used.

\section{Results}

Activation of MORs produces differential effects on locomotion and VTA-to-mAcbSh-projecting DA neurons in Oprm 1 112A/A and 112G/G mice

To unequivocally identify the VTA DA neurons in Oprm1 A112G mice for functional analysis, we generated DAT-Cre:A112G dou- ble knock-in mice by crossing A112G (Mague et al., 2009) and DAT-IRES-Cre mouse lines (Zhuang et al., 2005). To evaluate whether the DAT transgene affects A112G mouse behavior, we tested morphine-induced hyperactivity. Consistent with a previous report (Mague et al., 2009), 112G/G animals showed reduced hyperactivity induced by morphine administration (Fig. 1A).

To label the VTA DA neurons projecting to mAcbSh, we stereotaxically delivered AAV-DIO-EYFP virus into the VTA and red RetroBeads into the mAcbSh of the DAT-Cre:A112G mice (Fig. $1 B, C$ ). Whole-cell patch-clamp recordings were performed on these cells. As previously reported (Lammel et al., 2011), mesolimbic mAcbSh-projecting DA neurons have small soma size and high input resistance, and demonstrated spontaneous AP (sAP) activity and minor or no detectable hyperpolarizationinduced currents (Fig. 1D-H). No obvious differences were ob- 


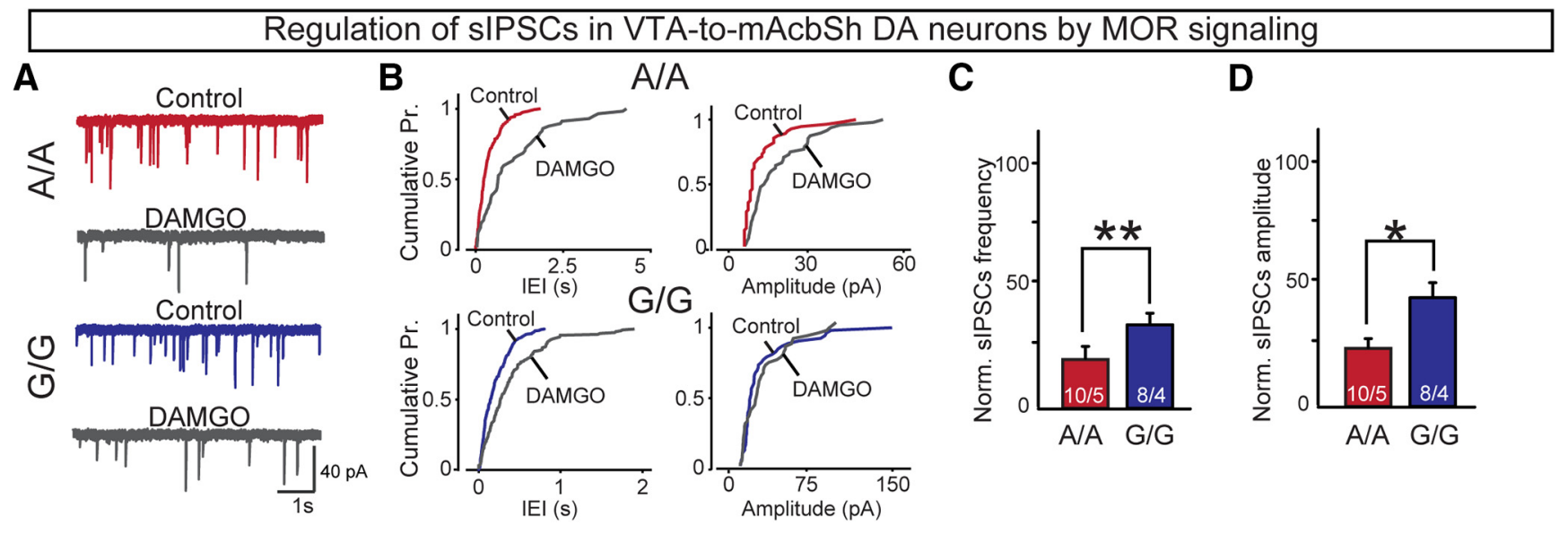

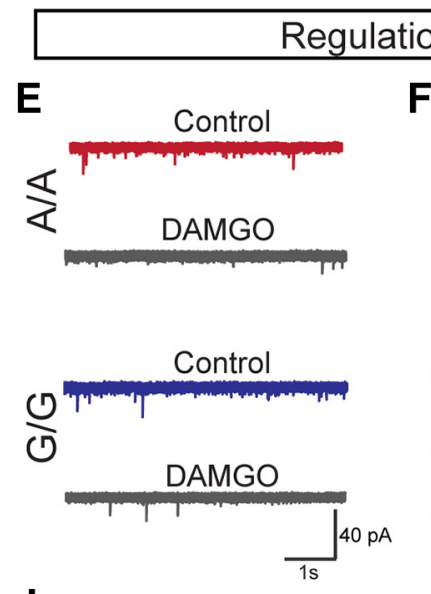

I

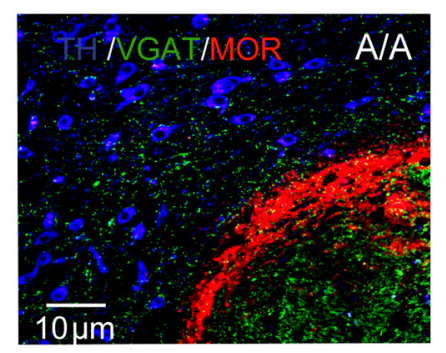

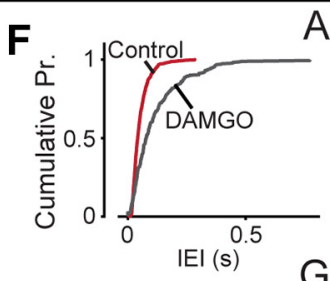

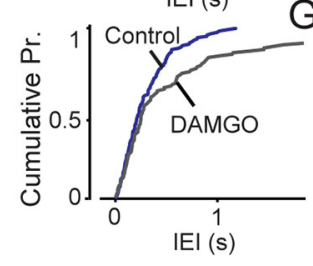

$G / G$

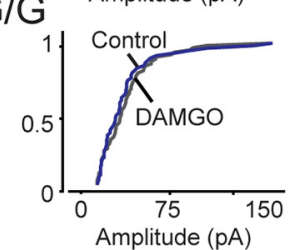

G

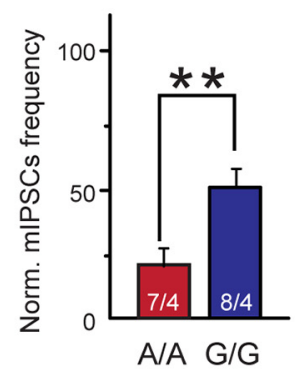

H

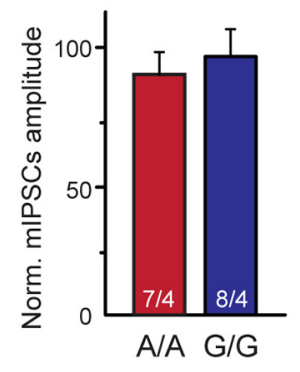

J
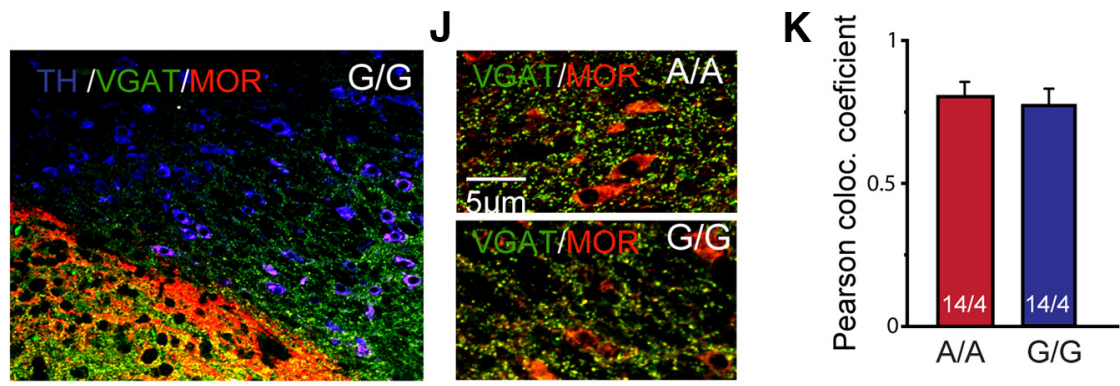

Figure 2. DAMG0 suppresses inhibitory synaptic strength in VTA-to-mAcbSh-projecting DA neurons in 112A/A and 112G/G mice. A, Representative traces of sIPSCs in VTA-to-mAcbSh-projecting DA neurons in the presence or absence (control) of DAMGO (1 $\mu \mathrm{M})$. B, Cumulative probability plots of IEls (112A/A: KS test, $p<0.001 ; 112 \mathrm{G} / \mathrm{G}$ : KS test, $p<0.01)$ and amplitudes (112A/A: KS test, $p<0.001 ; 112 \mathrm{G} / \mathrm{G}: \mathrm{KS}$ test, $p=0.559$ ) for sIPSCs in the presence or absence (control) of DAMG0.C, Pooled data for normalized sIPSC frequency. D, Pooled data for normalized sIPSC amplitude. $E$, Representative traces of mIPSCs in VTA-to-mAcbSh-projecting DA neurons in the presence or absence (control) of DAMG0. F, Cumulative probability plots of IEls (112A/A: KS test, $p<0.001 ; 112 \mathrm{G} / \mathrm{G}$ : KS test, $p<0.01$ ) and amplitudes (112A/A: KS test, $p<0.05 ; 112 \mathrm{G} / \mathrm{G}: \mathrm{KS}$ test, $p=0.873$ ) for mIPSCs in the presence or absence (control) of DAMG0. G, Pooled data for normalized mIPSC frequency. $\boldsymbol{H}$, Pooled data for normalized mIPSC amplitude. $\boldsymbol{I}, \boldsymbol{J}$, Fluorescent image showing colocalization of MOR and VGAT in VTA (DA neurons labeled with antibodies against TH). $\boldsymbol{K}$, Colocalization analysis of VGAT and MOR immunofluorescence. Data are mean \pm SEM. Number of neurons/number of animals are indicated in bars. One-way ANOVA was used to evaluate between-genotype statistical differences: ${ }^{*} p<0.05 ;{ }^{* *} p<0.01$.

served in basal synaptic transmission, including both sEPSCs and sIPSCs between mice carrying the A/A or G/G-alleles (Fig. $1 I-K$ ). However, their sAP activities were differentially modulated by the MOR agonist DAMGO. It strongly facilitated AP firing of the VTA-to-mAcbSh-projecting DA neurons in the 112A/A compared with $112 \mathrm{G} / \mathrm{G}$ mice $(112 \mathrm{~A} / \mathrm{A}: 2.0 \pm 0.2 \mathrm{~Hz}, n=16 / 6$, neurons/mice, $p<0.001$, paired $t$ test; $112 \mathrm{G} / \mathrm{G}: 1.3 \pm 0.09 \mathrm{~Hz}, n=$ $14 / 6$, neurons/mice, $p<0.01$, paired $t$ test) (Fig. $1 L-N$ ). These data suggest that VTA DA neurons in $112 \mathrm{G} / \mathrm{G}$ mice are less sensitive to MOR modulation, which correlates well with the behavioral effects observed with morphine.
Effects of DAMGO and morphine on inhibitory synaptic transmission in VTA-to-mAcbSh DA neurons in Oprm1 112A/G mice

To evaluate the impact of Oprm1 A112G on synaptic transmission in VTA DA-to-mAcbSh circuitry, we recorded sIPSCs in the absence or presence of $1 \mu \mathrm{M}$ DAMGO. In 112A/A mice, DAMGO suppressed $80.8 \pm 2.5 \%$ in frequencies $(n=10 / 5$, neurons/mice, $p<0.01$, paired $t$ test) of overall inhibitory synaptic drive (sIPSCs) onto DA neurons projecting to the mAcbSh, but in $112 \mathrm{G} / \mathrm{G}$ mice, DAMGO only suppressed $60.4 \pm 5.2 \%(n=8 / 4$, neurons/mice, $p<0.05$, paired $t$ test) of sIPSCs (Fig. $2 A-D$ ). To 

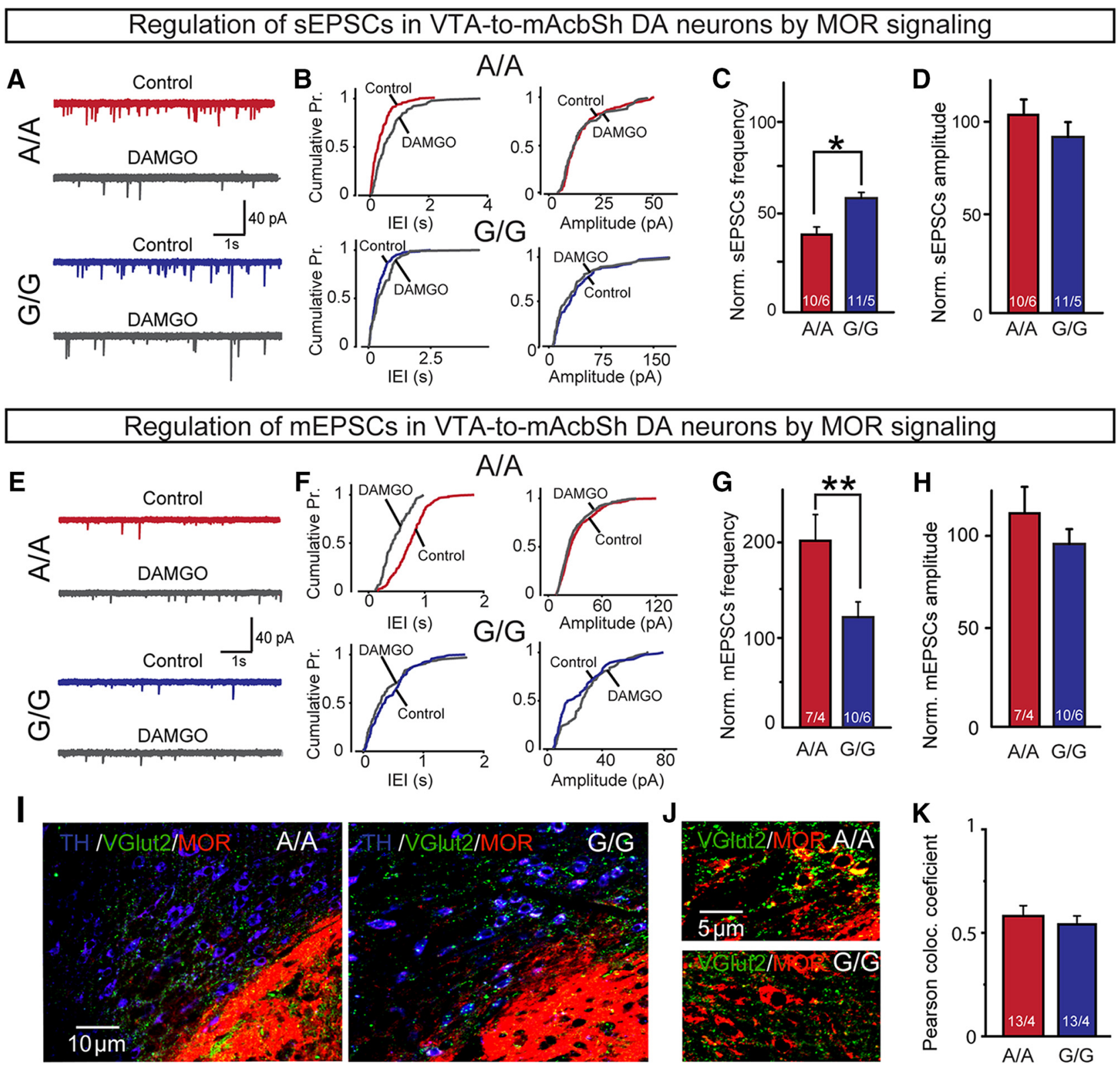

Figure 3. DAMGO suppresses excitatory synaptic transmission in VTA-to-mAcbSh-projecting DA neurons in $112 \mathrm{~A} / \mathrm{A}$ and $112 \mathrm{G} / \mathrm{G}$ mice. $\boldsymbol{A}$, Representative traces of sEPSCs in VTA-to-mAcbShprojecting DA neurons in the presence or absence (control) of DAMGO (1 $\mu \mathrm{M})$. $\boldsymbol{B}$, Cumulative probability plots of IEls (112A/A: KS test, $p<0.05 ; 112 \mathrm{G} / \mathrm{G}$ : KS test, $p<0.05)$ and amplitudes (112A/A: KS test, $p=0.741 ; 112 \mathrm{G} / \mathrm{G}$ : KS test, $p=0.693$ ) for sEPSCs in the presence or absence (control) of DAMG0. C, Pooled data for normalized sEPSC frequency. D, Pooled data for normalized sIPSC amplitude. $\boldsymbol{E}$, Representative traces of mEPSCs in VTA-to-mAcbSh-projecting DA neurons in the presence or absence (control) of DAMG0. $\boldsymbol{F}$, Cumulative probability plots of IEls (112A/A: KS test, $p<$ $0.001 ; 112 \mathrm{G} / \mathrm{G}: \mathrm{KS}$ test, $p=0.462$ ) and amplitudes (112A/A: KS test, $p=0.843 ; 112 \mathrm{G} / \mathrm{G}$ : KS test, $p=0.126)$ for mEPSCs in the presence or absence (control) of DAMG0. G, Pooled data for normalized mEPSC frequency. $\boldsymbol{H}$, Pooled data for normalized mEPSC amplitude. I, J, Fluorescent image showing colocalization of MOR and vesicular glutamate transporter 2 (VGlut2) in VTA DA neurons labeled with antibodies against TH. $\boldsymbol{K}$, Colocalization analysis of VGlut2 and MOR immunofluorescence. Data are mean \pm SEM. Number of neurons/number of animals are indicated in bars. One-way ANOVA was used to evaluate between-genotype statistical differences: ${ }^{*} p<0.05 ;{ }^{* *} p<0.01$.

discriminate whether the MOR acts presynaptically or postsynaptically to DA neurons, we also recorded mIPSCs. We observed that DAMGO suppressed the frequencies, but not amplitudes, of mIPSCs in VTA DA neurons: $77.1 \pm 4.0 \%(n=$ $7 / 4$, neurons/mice, $p<0.01$, paired $t$ test $)$ and $51.8 \pm 8.2 \%$ ( $n=8 / 4$, neurons/mice, $p<0.05$, paired $t$ test) in $112 \mathrm{~A} / \mathrm{A}$ and $112 \mathrm{G} / \mathrm{G}$, respectively, suggesting that the MOR reduced the presynaptic release probability of GABA (Fig. $2 E-H$ ). Using a validated MOR-specific antibody, we then conducted immuno- histochemistry to confirm that MORs are localized on presynaptic inhibitory terminals in the VTA. We labeled DA neurons using antibodies specific for TH and GABAergic terminals with antibodies against the VGAT. We found that VGAT and MOR puncta are colocalized in the VTA region (Fig. 2I-K). Based on these results, we concluded that MORs are present on inhibitory synaptic terminals in the VTA of both A- and G-allele carriers, and G-allele carriers are less responsive to the MOR agonist DAMGO. 


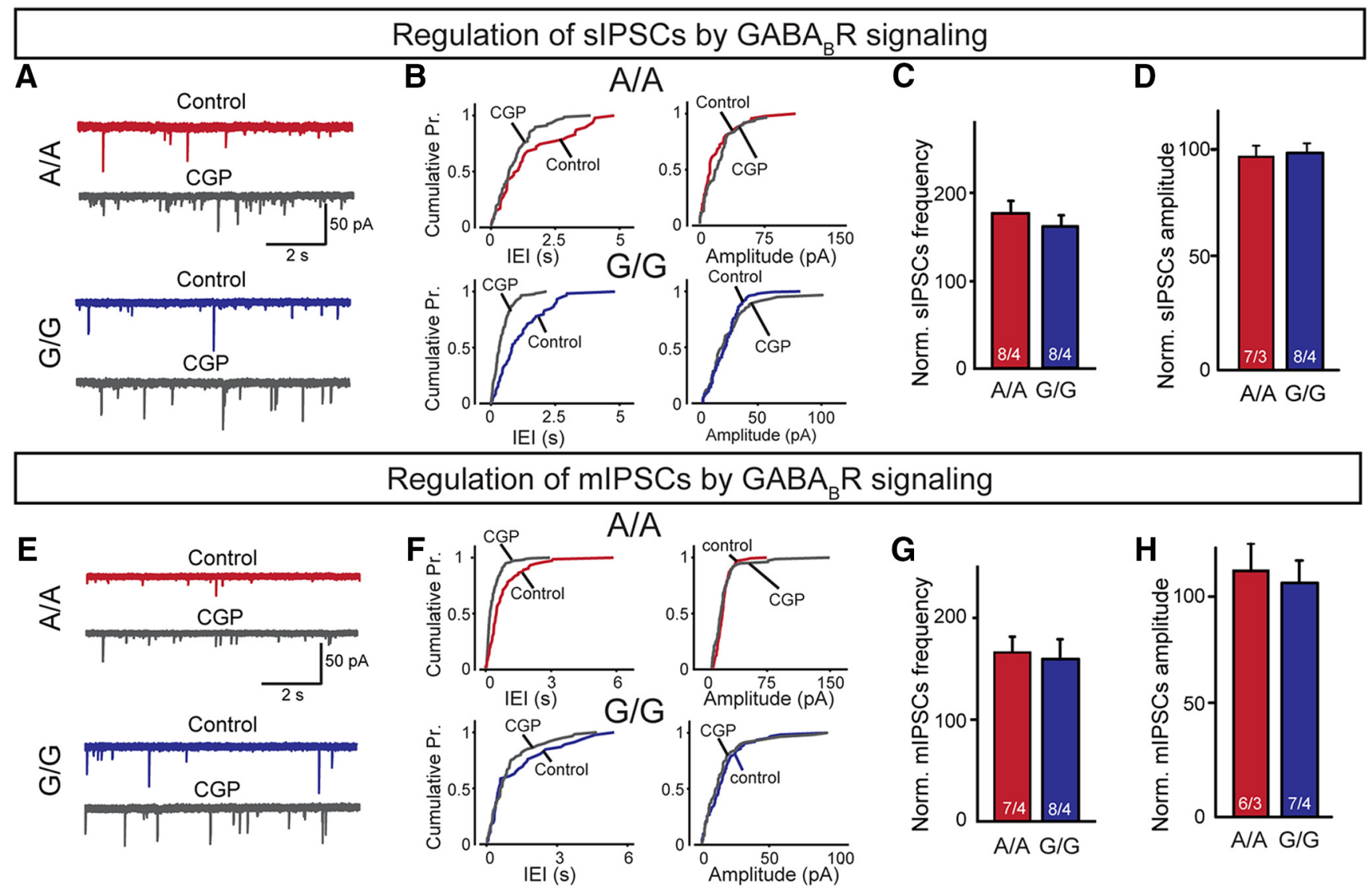

Figure 4. $\quad G_{A B A}{ }_{B} R s$ regulate inhibitory synaptic inputs of VTA-to-mAcbSh-projecting DA neurons in $112 \mathrm{~A} / \mathrm{A}$ and $112 \mathrm{G} / \mathrm{G}$ mice. $A$, Representative traces of sIPSCs in VTA-to-mAcbSh-projecting DA neurons in the presence or absence (control) of the $\mathrm{GABA}_{B} \mathrm{R}$ antagonist (GP $55845(1 \mu \mathrm{M})$. B, Cumulative probability plots of IEls (112A/A: KS test, $p<0.01 ; 112 \mathrm{G} / \mathrm{G}: \mathrm{KS}$ test, $\left.p<0.001\right)$ and amplitudes (112A/A: KS test, $p=0.661 ; 112 \mathrm{G} / \mathrm{G}$ : KS test, $p=0.681$ ) for sIPSCs in the presence or absence (control) of CGP 55845. C, Pooled data for normalized sIPSC frequency. D, Pooled data for normalized sIPSC amplitude. $E$, Representative traces of mIPSCS in VTA-to-mAcbSh-projecting DA neurons in the presence or absence (control) of (GP 55845. $F$, Cumulative probability plots of IEls (112A/A: KS test, $p=0.05 ; 112 \mathrm{G} / \mathrm{G}: \mathrm{KS}$ test, $p<0.05$ ) and amplitudes (112A/A: KS test, $p=0.869,112 \mathrm{G} / \mathrm{G}: \mathrm{KS}$ test, $p=0.764)$ for mIPSCs in the presence or absence (control) of (GP 55845 . G, Pooled data for normalized mIPSC frequency. $\boldsymbol{H}$, Pooled data for normalized mIPSC amplitude. Data are mean \pm SEM. Number of neurons/number of animals are indicated in bars. One-way ANOVA was used to evaluate between-genotype statistical differences.

\section{Effects of DAMGO on excitatory synaptic transmission in VTA-to-mAcbSh DA neurons in Oprm1 112A/G mice.}

Next, we evaluated the effect of DAMGO on excitatory synaptic transmission in VTA DA neurons projecting to the mAcbSh. We observed that MOR activation suppressed sEPSC frequency, but not amplitude, and to a lesser degree in the $112 \mathrm{G} / \mathrm{G}$ mice: $62.5 \pm$ $5.6(n=10 / 6$, neurons/mice, $p<0.001$, paired $t$ test $)$ and $38.5 \pm$ $6.9 \%(n=11 / 5$, neurons/mice, $p<0.01$, paired $t$ test $)$ in $112 \mathrm{~A} / \mathrm{A}$ and $112 \mathrm{G} / \mathrm{G}$, respectively (Fig. $3 A-D$ ). We then tested the impact of DAMGO on mEPSCs; and to our surprise, contrary to what we observed in sEPSCs, we found that DAMGO increased mEPSC frequency in $112 \mathrm{~A} / \mathrm{A}$ mice $(105.9 \pm 27.6, n=7 / 4$, neurons/mice, $p<0.05$, paired $t$ test), but not in $112 \mathrm{G} / \mathrm{G}$ animals (17.4 $\pm 6.8 \%$, $n=10 / 6$, neurons/mice, $p>0.05$, paired $t$ test) (Fig. $3 E-H$ ). Using immunohistochemistry, we confirmed that MORs have some colocalization with vGluT2 (Fig. 3I-K). The discrepancy in the effect on sEPSCs (suppression in both 112A/A and 112G/G mice) and mEPSCs (facilitation in 112A/A and no change in $112 \mathrm{G} / \mathrm{G}$ ) was puzzling. However, based on the fact that DAMGO also reduced GABA release (Fig. 2), we reasoned that it was possible that metabotropic $\mathrm{GABA}_{\mathrm{B}}$ receptors $\left(\mathrm{GABA}_{\mathrm{B}} \mathrm{Rs}\right)$ positioned at the excitatory presynaptic terminal could account for this phenomenon. Important, $\mathrm{GABA}_{\mathrm{B}} \mathrm{R}$-mediated regulation of glutamate release was previously reported in the VTA (Chen et al., 2015). The EPSCs were recorded only in the presence of picro- toxin, a $\mathrm{GABA}_{\mathrm{A}}$ receptor blocker, which would mean that GABA release per se was not affected. Thus, the reduction in GABA release, most likely caused by MOR activation, reduced the $\mathrm{GABA}_{\mathrm{B}} \mathrm{R}$-mediated presynaptic inhibition of glutamate release. This inhibition was enhanced in the 112A/A mice likely due to a stronger inhibitory effect on suppression of GABA release by MORs. However, in the 112G/G mice, the reduced suppression of GABA limited the extent of presynaptic inhibition by $\mathrm{GABA}_{\mathrm{B}} \mathrm{Rs}$ and resulted in less disinhibition of glutamate release.

The interaction of presynaptic $\mathrm{GABA}_{\mathrm{B}} \mathrm{Rs}$ and MORs in the VTA-to-mAcbSh-projecting DA neurons and the impact of Oprm1 112A/G SNPs

To test the hypothesis that presynaptic $\mathrm{GABA}_{\mathrm{B}} \mathrm{Rs}$ in the VTA modulate synaptic release, we recorded both EPSCs and IPSCs in the presence of specific blockers for $\mathrm{GABA}_{\mathrm{A}}$ and AMPA receptors, respectively, in the presence of the $\mathrm{GABA}_{\mathrm{B}} \mathrm{R}$ antagonist CGP $55845(1 \mu \mathrm{M})$. We observed that the frequencies of sEPSCs, sIPSCs, mEPSCs, and mIPSCs were all augmented (Figs. 4, 5), suggesting that the strong tonic inhibition mediated by $\mathrm{GABA}_{\mathrm{B}} \mathrm{Rs}$ plays an important role in modulating synaptic inputs to VTA DA neurons projecting to the $\mathrm{mAcbSh}$. There were no differences in the extent of $\mathrm{GABA}_{\mathrm{B}} \mathrm{R}$-mediated regulation on synaptic release between 112A/A and 112G/G mice (Figs. 4, 5). Interestingly, in 


\section{Regulation of SEPSCs by GABA $\mathrm{B}_{\mathrm{B}}$ signaling}
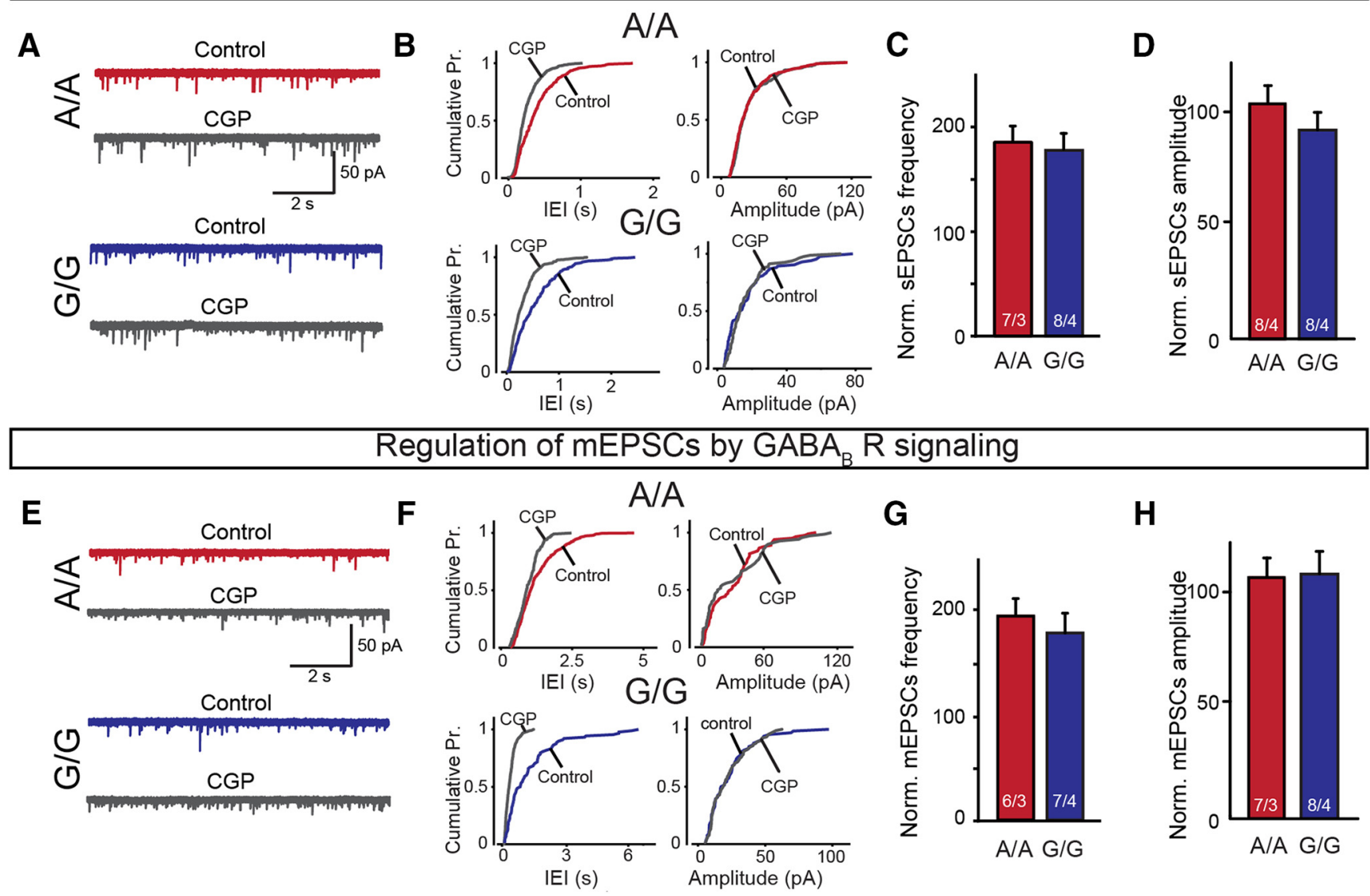

Figure 5. $\quad G_{A B A} B_{B}$ s regulate the excitatory synaptic inputs of VTA-to-mAcbSh-projecting DA neurons in $112 A / A$ and $112 G / G$ mice. $A$, Representative traces of sEPSCs in VTA-to-mAcbSh-projecting DA neurons in the presence or absence (control) of the GABA ${ }_{B} R$ antagonist CGP $55845(1 \mu \mathrm{M})$. B, Cumulative probability plots of IEls (112A/A: KS test, $p<0.05 ; 112 \mathrm{G} / \mathrm{G}$ : KS test, $\left.p<0.001\right)$ and amplitudes (112A/A: KS test, $p=0.851 ; 112 \mathrm{G} / \mathrm{G}:$ KS test, $p=0.873$ ) for sEPSCs in the presence or absence (control) of (GP 55845. C, Pooled data for normalized sEPSC frequency. $\boldsymbol{D}$, Pooled data for normalized sEPSC amplitudes in the presence or absence (control) of DAMGO. E, Representative traces of mEPSCs in VTA-to-mAcbSh-projecting DA neurons in the presence or absence (control) of CGP 55845. $\boldsymbol{F}$, Cumulative probability plots of IEls (112A/A: KS test, $p<0.05 ; 112 \mathrm{G} / \mathrm{G}: \mathrm{KS}$ test, $p<0.001)$ and amplitudes (112A/A: KS test, $p=0.193 ; 112 \mathrm{G} / \mathrm{G}: \mathrm{KS}$ test, $p=0.810)$ for mEPSCs in the presence or absence (control) of CGP 55845. G, Pooled data for normalized mEPSC frequency. $\boldsymbol{H}$, Pooled data for normalized mEPSC amplitude. Data are mean \pm SEM. Number of neurons/ number of animals are indicated in bars. One-way ANOVA was used to evaluate between-genotype statistical differences.

the presence of the $\mathrm{GABA}_{\mathrm{B}} \mathrm{R}$ antagonist, DAMGO suppressed mEPSCs and mIPSCs in both $112 \mathrm{~A} / \mathrm{A}$ and $112 \mathrm{G} / \mathrm{G}$ mice, but with a stronger effect in A/A mice (Figs. 6, 7). Because $\mathrm{GABA}_{\mathrm{B}} \mathrm{Rs}$ and MORs are both GPCRs associated with Gi/Go effectors (Bettler et al., 2004), the difference between 112A/A and $112 \mathrm{G} / \mathrm{G}$ can most likely be attributed to differences in MOR-mediated signaling.

We also examined the dose dependency of DAMGO and morphine on sIPSCs in the presence of the AMPA receptor blocker (CNQX) and $\mathrm{GABA}_{\mathrm{B}} \mathrm{R}$ blocker (CGP 55845). We found that both DAMGO and morphine suppressed the frequencies of sIPSCs in a dose-dependent manner (Fig. 8). Importantly, DAMGOinduced suppression of sIPSCs was reversible with administration of the MOR antagonist naltrexone. Interestingly, 112A/A mice responded stronger to DAMGO administration (Fig. 8A$C)$. Similarly, morphine also induced suppression of sIPSCs in the VTA for both genotypes, in a dose-dependent manner, with a stronger response in 112A/A mice (Fig. $8 D-F$ ). Although previous work has reported no obvious acute desensitization of presynaptic MOR signaling (Fyfe et al., 2010; Pennock and Hentges, 2011; Lowe and Bailey, 2015), in these mesolimbic mAcbSh-projecting DA neurons, we observed some level of decreasing efficacy of
sIPSC suppression under longitudinal exposure of increasing concentrations of DAMGO but not morphine (Fig. 8).

MORs and $\mathrm{GABA}_{\mathrm{B}}$ Rs orchestrate VTA-to-mAcbSh-projecting DA neurocircuitry in Oprm1 112A/A and 112G/G mice

In the VTA-to-mAcbSh-projecting DA neurons, we found that both inhibitory and excitatory synaptic inputs onto the VTA-to$\mathrm{mAcbSh}$-projecting DA neurons are regulated by presynaptic MORs. Furthermore, MORs in mice with the $112 \mathrm{G} / \mathrm{G}$ allele were less efficacious in regulating this circuitry (Figs. 3, 4). We demonstrated that presynaptic $\mathrm{GABA}_{\mathrm{B}} \mathrm{Rs}$ have similar efficacies in modulating synaptic release in both $112 \mathrm{~A} / \mathrm{A}$ and $112 \mathrm{G} / \mathrm{G}$ mice (Figs. 4, 5) and MORs interact with $\mathrm{GABA}_{\mathrm{B}}$ Rs in the VTA (Figs. 6, 7). The basal AP firing of VTA-to-mAcbSh-projecting DA neurons was $1.3 \pm 0.1(\mathrm{~A} / \mathrm{A})$ and $1.3 \pm 0.1(\mathrm{G} / \mathrm{G})$; on average, sEPSC frequency was $6.29 \pm 3.54(\mathrm{~A} / \mathrm{A})$ and $7.01 \pm 2.11(\mathrm{G} / \mathrm{G})$, and sIPSC was $5.08 \pm 3.71(\mathrm{~A} / \mathrm{A})$ and $4.83 \pm 3.62(\mathrm{G} / \mathrm{G})$. Meanwhile, these neurons had a high input resistance (Fig. 1). Therefore, MOR-GABA ${ }_{B} R$ regulation on synaptic transmission may affect DA neuronal firing. To test this, we analyzed AP firing in DA neurons in the cell-attached recording configuration. Bath application of the $\mathrm{GABA}_{\mathrm{A}} \mathrm{R}$ antagonist picrotoxin $(50 \mu \mathrm{M}), \mathrm{GABA}_{\mathrm{B}} \mathrm{R}$ 


\section{Effects of MOR and $\mathrm{GABA}_{\mathrm{B}} \mathrm{R}$ signaling on sIPSCs}
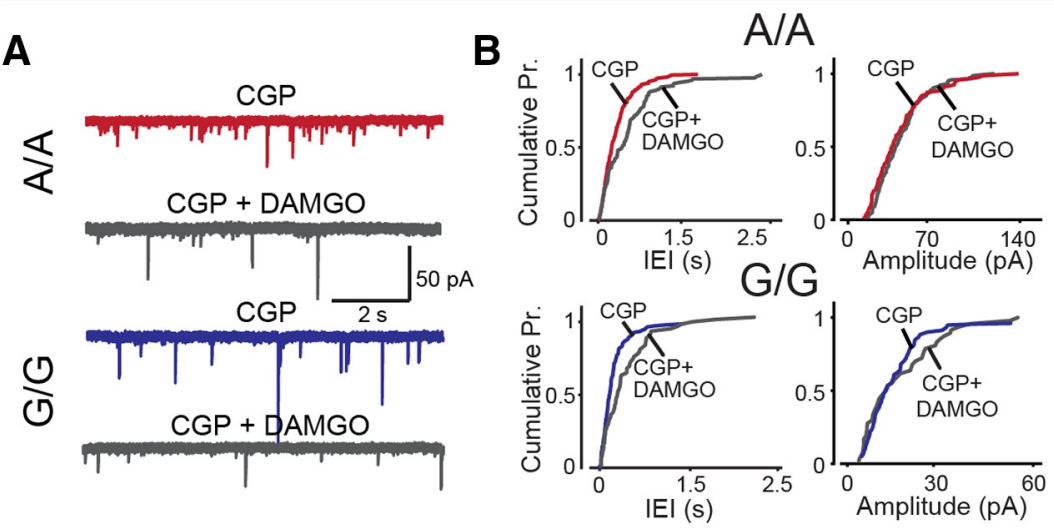

C

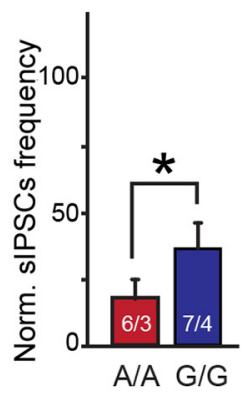

D

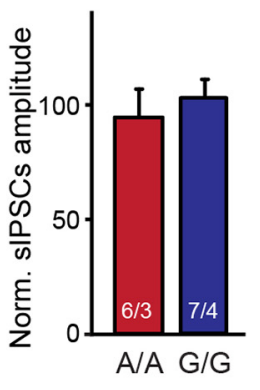

Effects of MOR and $G_{A B A} R$ signaling on mIPSCs

E
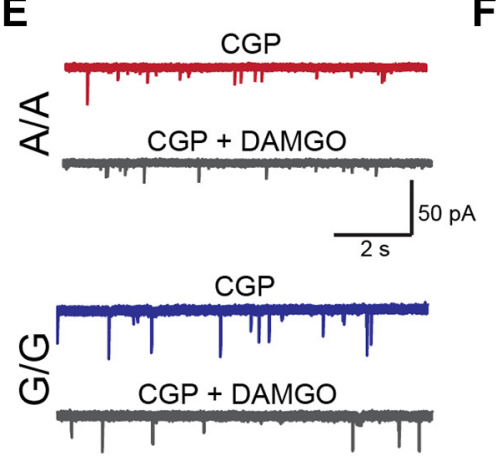

$\mathbf{F}$
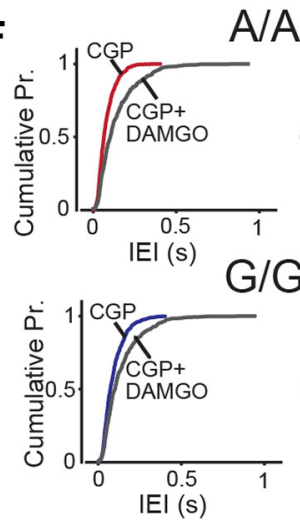

$\mathrm{A} / \mathrm{A}$
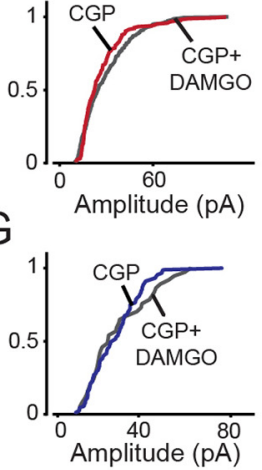

G

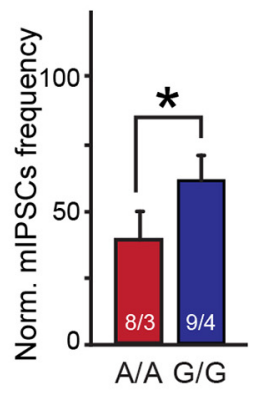

H

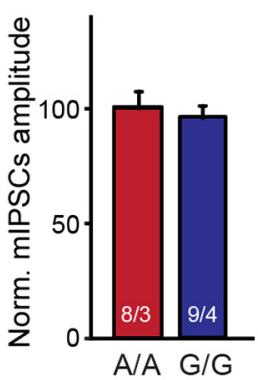

Figure 6. MORs regulate the inhibitory synaptic inputs of VTA-to-mAcbSh-projecting DA neurons in the absence of $G A B A_{B}$ regulation in $112 A / A$ and $112 G / G$ mice. $A$, Representative traces of sIPSCs in VTA-to-mAcbSh-projecting DA neurons in the presence or absence (control) of the $\mathrm{GABA}_{B} R$ antagonist CGP $55845(1 \mu \mathrm{M})$ and the MOR agonist DAMGO (1 $\left.\mu \mathrm{M}\right)$. $\boldsymbol{B}$, Cumulative probability plots of IEls (112A/A: KS test, $p<0.05 ; 112 \mathrm{G} / \mathrm{G}$ : KS test, $p<0.01)$ and amplitudes (112A/A: KS test, $p=0.816 ; 112 \mathrm{G} / \mathrm{G}: \mathrm{KS}$ test, $p=0.431$ ) for sIPSCs in the presence or absence (control) of (GP $55845+$ DAMG0. C, Pooled data for normalized sIPSC frequency. D, Pooled data for normalized sIPSC amplitude. E, Representative traces of mIPSCs in VTA-to-mAcbSh-projecting DA neurons in the presence or absence (control) of (GP 55845+DAMG0. $F$, Cumulative probability plots of IEls (112A/A: KS test, $p<0.01 ; 112 \mathrm{G} / \mathrm{G}: \mathrm{KS}$ test, $p<0.05)$ and amplitudes (112A/A: KS test, $p=0.561$; $112 \mathrm{G} / \mathrm{G}: \mathrm{KS}$ test,$p=0.547$ ) for mIPSCs in the presence or absence (control) of GGP55845 + DAMGO. G, Pooled data for normalized mIPSC frequency. $\boldsymbol{H}$, Pooled data for normalized mIPSC amplitude. Data are mean \pm SEM. Number of neurons/number of animals are indicated in bars. One-way ANOVA was used to evaluate between-genotypes statistical differences: ${ }^{*} p<0.05$.

antagonist CGP $55845(1 \mu \mathrm{M})$, and the MOR agonist DAMGO $(1 \mu \mathrm{M})$ induced shifts in the firing of DA neurons (Fig. $9 A, B)$. As expected, picrotoxin facilitated firing of DA neurons in both genotypes: $112 \mathrm{~A} / \mathrm{A}, 1.5 \pm 0.1(n=6 / 5$, neurons/mice, $p<0.01$, paired $t$ test); and $112 \mathrm{G} / \mathrm{G}, 1.4 \pm 0.08(n=6 / 5$, neurons/mice, $p<0.05$, paired $t$ test); and CGP 55845 further potentiated the firing of DA neurons with no difference between genotypes: $112 \mathrm{~A} / \mathrm{A}, 1.7 \pm 0.08(n=6 / 5$, neurons/mice, $p<0.05$, paired [ $t$ test $)$; and $112 \mathrm{G} / \mathrm{G}, 1.87 \pm 0.09(n=6 / 5$, neurons/mice, $p<$ 0.01 , paired $t$ test). When both $\mathrm{GABA}_{\mathrm{A}} \mathrm{Rs}$ and $\mathrm{GABA}_{\mathrm{B}} \mathrm{Rs}$ were blocked, firing of DA neurons depended on the intrinsic firing properties of these neurons and on excitatory synaptic drive. To confirm that the MOR indeed regulates glutamate release onto DA to mAcbSh neurons and modulates activity of these cells, we next applied DAMGO in the presence of picrotoxin and CGP 55845. We observed that, in 112A/A mice, DAMGO suppressed the firing of neurons: $1.3 \pm 0.07(n=6 / 5$, neurons/mice, $p>$ 0.05 , paired $t$ test), whereas $112 \mathrm{G} / \mathrm{G}$ DA neurons did not respond to the MOR agonist $(1.7 \pm 0.08, n=6 / 5$, neurons/mice, $p<0.01$, paired $t$ test), again suggesting a loss-of-function phenotype in minor allele carriers (Fig. 9).

\section{Discussion}

In a murine model of human OPRM1 A118G SNP (rs1799971), we demonstrate that Oprm $1112 \mathrm{G} / \mathrm{G}$ allele carriers display altered MOR signaling, leading to attenuated modulation of both excitatory and inhibitory synaptic terminals in mesolimbic neurocircuitry, leading to a milder shift in DA neuronal AP firing. This circuit is critically involved in processing reward and is associated with addiction (Kauer and Malenka, 2007). Interestingly, we found no difference between genotypes (A/A vs $\mathrm{G} / \mathrm{G}$ ) in $\mathrm{GABA}_{\mathrm{B}} \mathrm{R}$-mediated modulation of excitatory and inhibitory synaptic inputs in the VTA-to-mAcbSh DA neurons. However, we observed that activation of presynaptic MORs in the VTA induced a $\mathrm{GABA}_{\mathrm{B}} \mathrm{R}$-dependent shift in DA neuronal firing, suggesting an interaction between signaling mediated by these two receptors (Fig. 9). These findings provide insight into the behavioral outcomes of subjects with A118G SNPs when exposed to drugs of abuse.

\section{Behavioral alterations in rodent models of OPRM1 A118G SNPs}

The A118G SNP is associated with an altered response to drugs of abuse; however, some studies have reported divergent ef- 


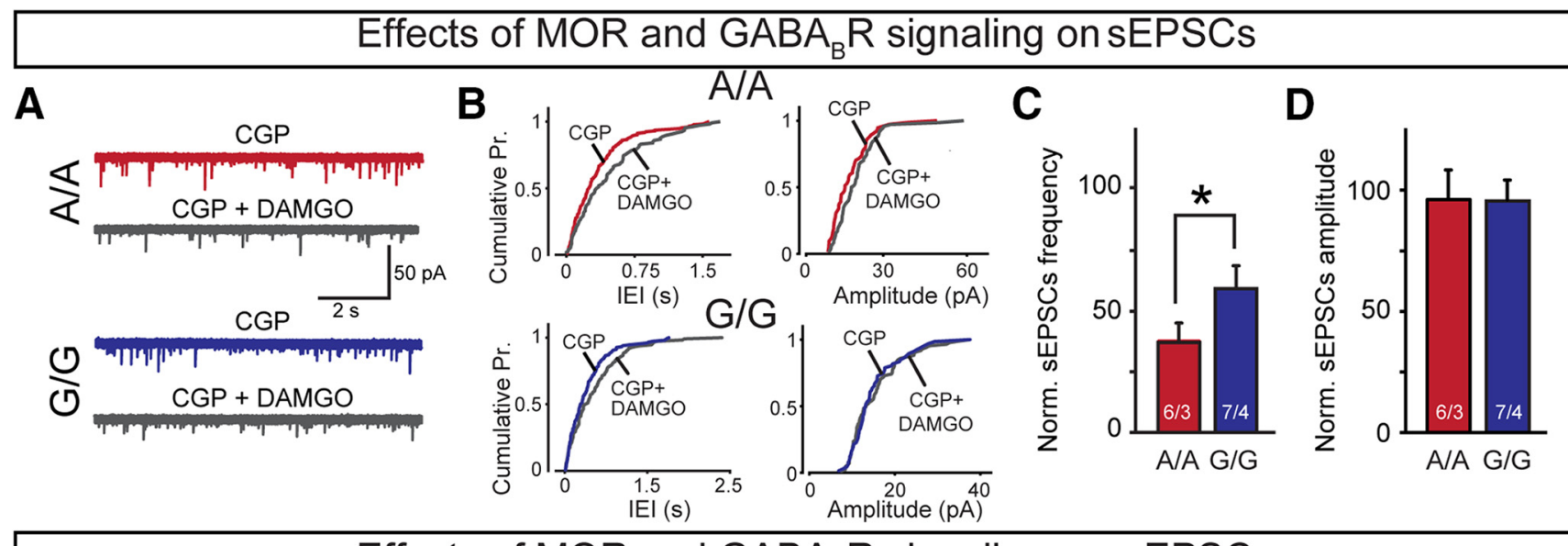

Effects of MOR and GABA ${ }_{B} R$ signaling on mEPSCs
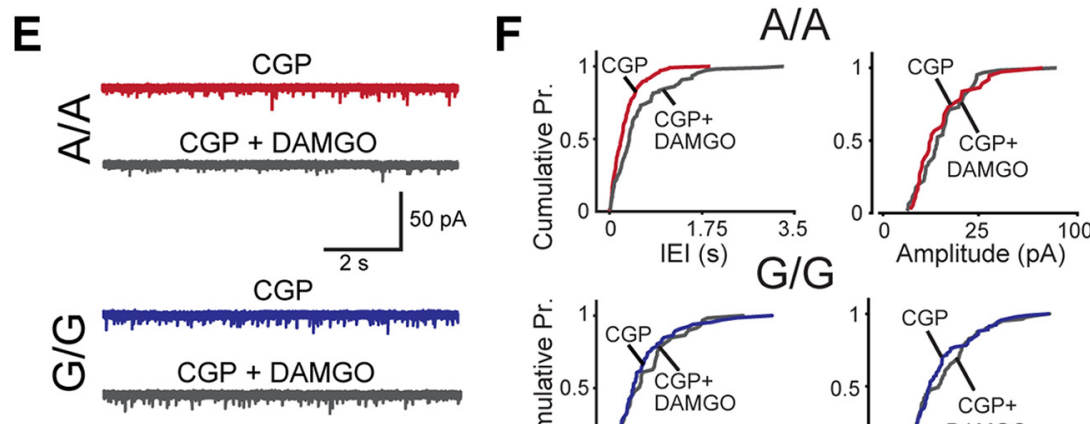

G

H
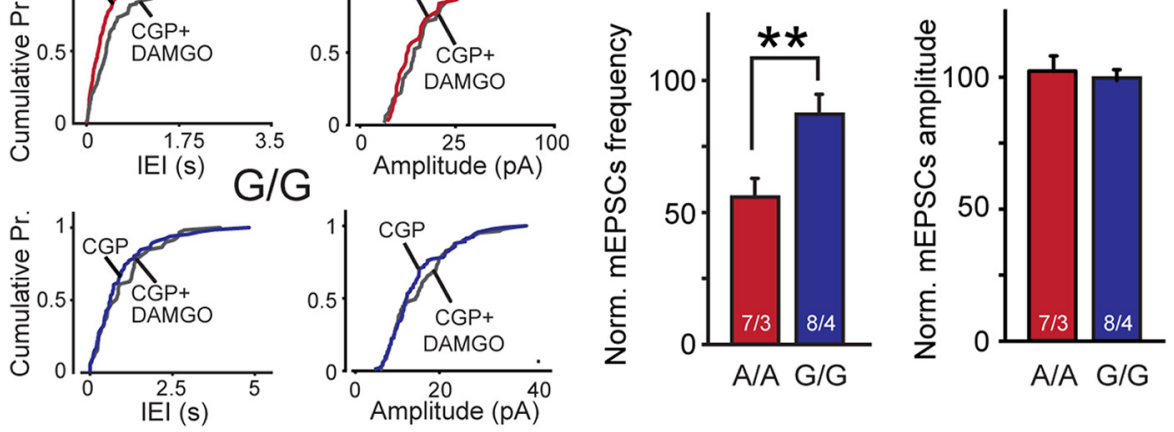

Figure 7. MORs regulate the excitatory synaptic inputs in VTA-to-mAcbSh-projecting DA neurons in the absence of $G A B A_{B}$ regulation in $112 \mathrm{~A} / \mathrm{A}$ and $112 \mathrm{G} / \mathrm{G}$ mice. $A$, Representative traces of SEPSCs in VTA-to-mAcbSh-projecting DA neurons in the presence or absence (control) of the $\mathrm{GABA}_{\mathrm{B}} \mathrm{R}$ antagonist CGP $55845(1 \mu \mathrm{M})$ and the MOR agonist DAMGO (1 $\left.\mu \mathrm{M}\right)$. $\boldsymbol{B}$, Cumulative probability plots of IEls (112A/A: KS test, $p<0.05 ; 112 \mathrm{G} / \mathrm{G}$ : KS test, $p<0.05$ ) and amplitudes (112A/A: KS test, $p=0.561 ; 112 \mathrm{G} / \mathrm{G}: \mathrm{KS}$ test, $p=0.769$ ) for sEPSCs in the presence or absence (control) of CGP 55845 + DAMG0.C, Pooled data for normalized sEPSC frequency. D, Pooled data for normalized sEPSC amplitude. $E$, Representative traces of mEPSCs in VTA-to-mAcbSh-projecting DA neurons in the presence or absence (control) of (GP 55845+DAMG0. $\boldsymbol{F}$, Cumulative probability plots of IEls (112A/A: KS test, $p<0.01 ; 112 \mathrm{G} / \mathrm{G}: \mathrm{KS}$ test, $p=0.291$ ) and amplitudes (112A/A: KS test, $p=0.662$; $112 \mathrm{G} / \mathrm{G}$ : KS test, $p=0.318$ ) for mEPSCs in the presence or absence (control) of CGP 55845+DAMG0. G, Pooled data for normalized mEPSC frequency. $\boldsymbol{H}$, Pooled data for normalized mEPSC amplitude. Data are mean \pm SEM. Number of neurons/number of animals are indicated in bars. One-way ANOVA was used to evaluate between-genotype statistical differences: ${ }^{*} p<0.05$; ${ }^{* *} p<0.01$.

fects (Ray and Hutchison, 2004; Ehlers et al., 2008; Miranda et al., 2010; Koller et al., 2012; Enoch, 2013; Sloan et al., 2018). Significant behavioral differences between the two genotypes have been reported in two mouse models of the A118G SNP: that is, the A112G knock-in and "humanized" A118G mouse models (Mague et al., 2009; Bilbao et al., 2015; Browne et al., 2017). In the $A 112 \mathrm{G}$ mouse model, it was reported that morphine-induced hyperactivity was blunted in G/G mice compared with those in A/A mice (Mague et al., 2009), which we also confirmed in the current study (Fig. $1 A$ ). In addition, it has been shown previously that the $\mathrm{G}$ allele is associated with an increase in home-cage dominance and increased motivation for nonaggressive social interactions (Briand et al., 2015); and it has also been shown that G-allele carrier mice have attenuated analgesic, anxiolytic, and hyperlocomotive effects from buprenorphine (Browne et al., 2017). In the humanized Oprm1 A118G mouse model, it has been shown that the effects of opioid antagonism on alcohol reward and consumption are affected (Bilbao et al., 2015). Thus, these mice are a genetically tractable and biologically accessible experimental model system to identify functional differences in MORs, which mediate many of these behavioral effects.
Impact of OPRM1 A118 gene variant (N40D MORs) on synaptic regulation in mesolimbic DA neurons

It has been hypothesized that the addictive properties of opioids are associated with their stimulation of the DA system: opioid agonists induce DA release in the NAc (Acb) when mice selfadminister them specifically into the VTA (Pentney and Gratton, 1991; Devine et al., 1993; Devine and Wise, 1994). An earlier study indicated that MOR agonists stimulate DA neurons indirectly through the suppression of inhibitory neurons in the VTA, which causes disinhibition of DA neurons (Johnson and North, 1992). Thus, a predominant theory in the field is that the reinforcing properties of opioids are mediated by MORs located on GABAergic terminals in the VTA. Upon activation, GABA release onto DA neurons is decreased, resulting in increased firing of these neurons. The subsequent increase of dopamine in the Acb is associated with drug reward and reinforcement (Nestler, 2005; Chen et al., 2015). However, it has also been demonstrated that VTA GABAergic neurons are less responsive to MOR agonists, compared with interneurons from other brain regions synapsing onto VTA DA neurons (Matsui et al., 2014), and excitatory transmission in the VTA can also be suppressed by MOR agonism (Bonci and Malenka, 1999). It is 
A DAMGO

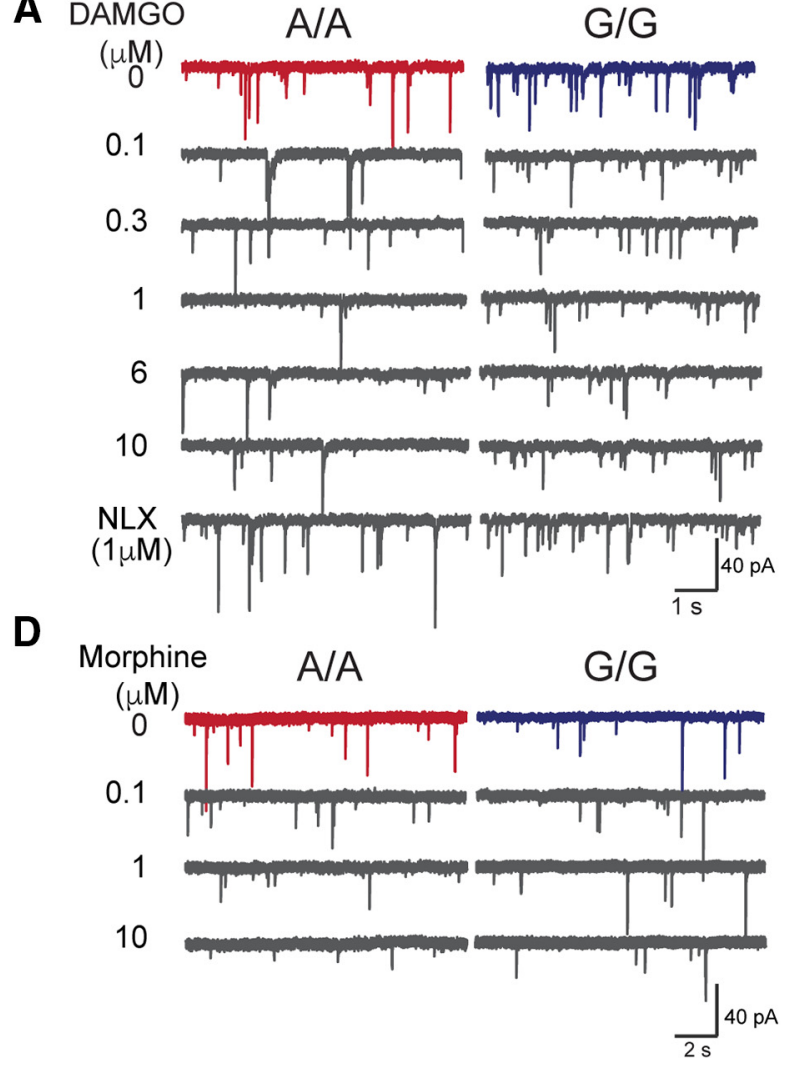

B

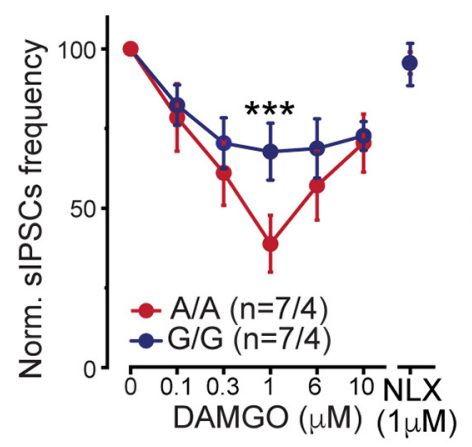

$\mathbf{E}$

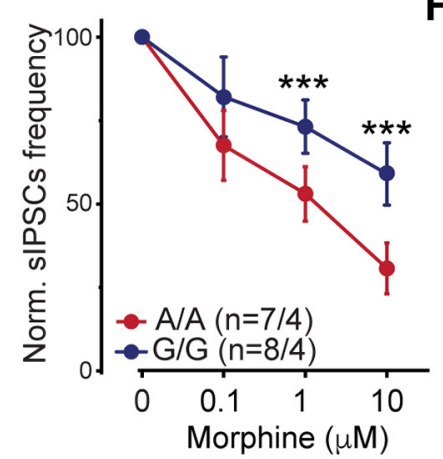

C

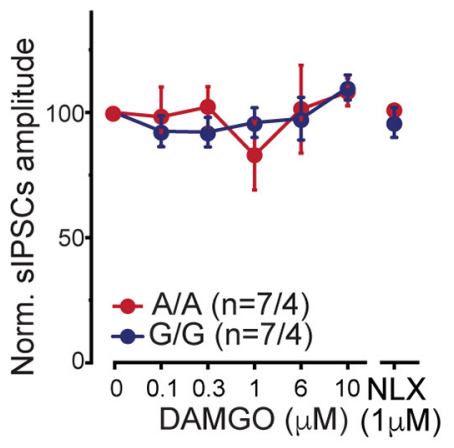

Figure 8. VTA-to-mAcbSh-projecting DA neurons respond differentially to various concentrations of DAMG0 and morphine in Oprm $1112 \mathrm{~A} / \mathrm{A}$ and $112 \mathrm{G} / \mathrm{G}$ mice. $A$, Representative traces of sIPSCS, recorded in the presence of the $G_{A B A} R$ blocker from VTA-to-mAcbSh-projecting DA neurons in response to increasing concentrations of DAMGO $(0.1-10 \mu \mathrm{M})$. B, Pooled data for normalized sIPSC frequency. $C$, Pooled data for normalized sIPSC amplitude. $\boldsymbol{D}$, Representative traces of $s$ IPSCs, recorded in the presence of $G A B A_{B} R$ blockers, from VTA-to-mAcbSh-projecting DA neurons in response to increasing concentrations of morphine $(0.1-10 \mu \mathrm{M})$. E, Pooled data for normalized sIPSC frequency. F, Pooled data for normalized sIPSC amplitude. Data are mean \pm SEM. $n$ values are indicated in the plots. One-way ANOVA was used to evaluate between genotype statistical difference: ${ }^{* *} p<0.001$.

A

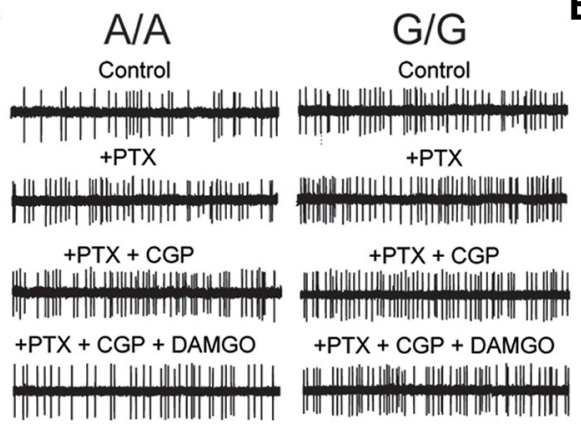

B

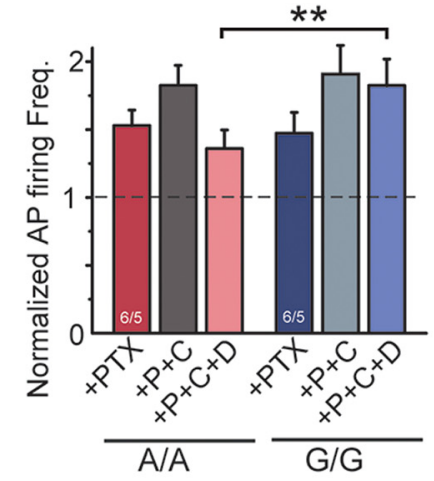

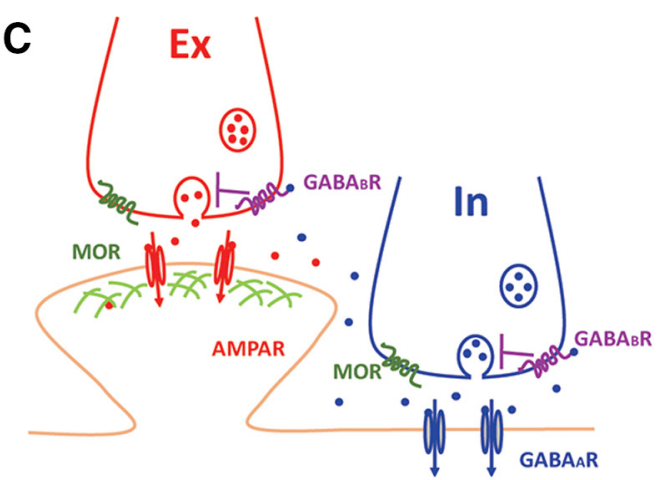

Figure 9. Modulation of VTA-to-mAcbSh DA neuronal firing by MORs and $G A B A_{B} R s$ in $112 A / A$ and $112 G / G$ mice. $A$, Example traces of sAP firing, recorded in the cell-attached configuration, from VTA-to-mAcbSh-projecting DA neurons; Picrotoxin (PTX or P, $50 \mu \mathrm{m}),(G P 55845(C, 1 \mu \mathrm{m})$, and DAMG0 (D, $1 \mu \mathrm{m}$ ) were added consecutively to record from 112A/A and 112G/G mice VTA brain slices. $B$, Pooled data of normalized AP firing rates under different conditions. Data are mean \pm SEM. Bars represent the number of neurons/number of animals. One-way ANOVA was used to evaluate between-genotype statistical differences: ${ }^{* *} p<0.01$. C, Schematic showing that MORs and $G_{A B A}$ Rs coordinate in regulating synaptic transmission in the VTA-to-mAcbSh-projecting DA neurons.

important to note that VTA DA neurons are also heterogeneous (Lammel et al., 2011; Root et al., 2014). For example, activation of mesolimbic VTA DA neurons is associated with reward, whereas activation of mesocortical DA neurons mediates aversion (Lammel et al., 2011).

In the current study, we focused on the mesolimbic mAcbShprojecting VTA DA neurons and observed that application of the MOR agonist DAMGO excites DA neurons in mice with the Oprm1 A-allele, but not in those with the G-allele (Fig. $1 L-N$ ).
We propose that the minor allele $(\mathrm{G} / \mathrm{G})$ causes a loss of function in MOR signaling. First, morphine-induced hyperactivity, as well as synaptic suppression, are both reduced in $112 \mathrm{G} / \mathrm{G}$ mice (Figs. $1 A, 8 D-F)$. Consistent with our findings, previous studies found that $112 \mathrm{G} / \mathrm{G}$ mice exhibit a blunted response to morphine/ buprenorphine-induced locomotor activity (Mague et al., 2009; Browne et al., 2017). Moreover, it was found that both male and female G/G mice self-administered more heroin than A/A mice over a $10 \mathrm{~d}$ period (Zhang et al., 2015). Second, at the synaptic 
level, MOR activation in G/G mice led to reduced suppression of both excitatory and inhibitory synaptic inputs to mesolimbic DA neurons (Figs. 2, 6, 7), leading to a smaller shift in AP firing of DA neurons (Fig. 9) and a potentially lower release of DA into the Acb. In support of our findings, a previous study on A118G humanized mice also reported that morphine reduced mIPSC frequency in DA neurons in A/A mice but not in G/G mice (Robinson et al., 2015). Although no differences in affinity have been observed between N40 (OPRM1 118 A/A) and D40 (i.e., OPRM1 118G/G) MOR toward ligand binding (Robinson et al., 2015), it has also been reported that binding affinity could be modified by gene variants (Bond et al., 1998). Therefore, detailed molecular mechanisms associated with differential regulation of synaptic transmission by MOR variants requires further elucidation.

The MOR is a GPCR whose activation causes inhibition of adenylyl cyclase and voltage-dependent calcium channels, and activation of inwardly rectifying potassium channels (Al-Hasani and Bruchas, 2011), ultimately leading to suppression of synaptic release. MOR D40 (G/G) caused deficits in MOR signaling and consequently differently regulated synaptic transmission (Figs. 2, 3, 6, 7). Importantly, the presynaptic regulation of synaptic release mediated by $\mathrm{GABA}_{\mathrm{B}}$ Rs (Cameron and Williams, 1993; Edwards et al., 2017), another GPCR, is not different between the A/A and G/G genotypes (Figs. 4, 5), suggesting that intracellular G-protein-coupled signaling is likely intact. However, it has also been reported that MORs and $\mathrm{GABA}_{\mathrm{B}}$ Rs may be differentially coupled to downstream effectors (Bagley, 2014). Nevertheless, it is apparent that MORs and $\mathrm{GABA}_{\mathrm{B}}$ Rs coordinate the firing of VTA DA neurons (Fig. 9). A loss of function in the minor allele caused differential outcomes, which might account for the different reward behaviors induced by drugs of abuse (Fig. 1A) (Ramchandani et al., 2011; Bilbao et al., 2015; Robinson et al., 2015; Zhang et al., 2015; Browne et al., 2017) or other types of behavior (Briand et al., 2015).

Interestingly, previous reports suggested no obvious acute desensitization of presynaptic MOR signaling (Fyfe et al., 2010; Pennock and Hentges, 2011; Lowe and Bailey, 2015). However, in mesolimbic mAcbSh-projecting DA neurons, we observed some level of decreasing efficacy of sIPSC suppression when increasing concentrations of DAMGO were applied in the presence of CNQX and CGP 55845 (Fig. 8A,B). This was not observed when increasing concentrations of morphine were applied (Fig. 8D,E). In VTA GABAergic nerve terminals, during prolonged presence of Met-enkephalin or direct activation of PKC, similar MOR desensitization was observed (Lowe and Bailey, 2015). The desensitizing effects of DAMGO observed in VTA-to-mAcbSh DA neurons potentially can be limited to this specific subgroup of VTA DA neurons (Fig. $8 A, B$ ). Or, alternatively, in these cells, under our recording conditions, different levels of intracellular PKC activities were involved (Lowe and Bailey, 2015). Clearly, further detailed analyses are needed in addressing the presynaptic dynamics of MOR regulation.

\section{Future perspectives}

Over the past two decades, human genetic approaches have identified hundreds of gene variants that affect a person's likelihood of developing drug dependence (Agrawal et al., 2012; Ducci and Goldman, 2012). However, in the vast majority of cases, the molecular mechanisms of how these alleles confer risk of disease are unknown; thus, this genetic information alone cannot be used to develop novel interventions. The present study provides a better understanding on the neurobiological and behavioral mechanisms that underlie risk of addiction development in carriers of the A118G SNP in OPRM1. One of the main findings from this work demonstrates that MOR activation produced less inhibition of neurotransmitter release in the $112 \mathrm{G} / \mathrm{G}$ mice, resulting in lower DA neuron firing in the presence of the opioids. This is in agreement with behavioral studies in these mice, where females do not find morphine rewarding in a conditioned place preference test (Mague et al., 2009). A lack of reward and/or lower dopamine release following opioids could reflect an insensitivity to MOR agonists. In such a case, individuals may require greater amounts of a drug to generate a positive experience, resulting in an increase in drug-taking behavior, a hallmark of opioid use disorders.

Because of the high prevalence of opioid addiction and a high prevalence of the A118G minor allele in human populations (Bergen et al., 1997; Gelernter et al., 1999; Tan et al., 2003; Mague and Blendy, 2010), it is important to gain a more mechanistic and functional understanding of MORs with different SNPs (Lötsch and Geisslinger, 2005) by using mouse (Mague et al., 2009; Bilbao et al., 2015) as well as using human neuronal models (Scarnati et al., 2019). In the rodent model, high heterogeneity of VTA neurocircuitry (Watabe-Uchida et al., 2012; Matsui et al., 2014; Beier et al., 2015) and possible gender-dependent implications (Kanaji et al., 2014; Browne et al., 2017) should be considered. Moreover, given the discrepancy of findings related to A118G SNPs, it is also likely that species-specific-dependent mechanisms are involved; recent developments in human stem cell and human neural stem cell technology (Prytkova et al., 2018; Scarnati et al., 2019) may help facilitate the study of SNPs in a human neuronal context.

\section{References}

Agrawal A, Verweij KJ, Gillespie NA, Heath AC, Lessov-Schlaggar CN, Martin NG, Nelson EC, Slutske WS, Whitfield JB, Lynskey MT (2012) The genetics of addiction: a translational perspective. Transl Psychiatry 2:e140.

Al-Hasani R, Bruchas MR (2011) Molecular mechanisms of opioid receptordependent signaling and behavior. Anesthesiology 115:1363-1381.

Bagley EE (2014) Opioid and GABAB receptors differentially couple to an adenylyl cyclase/protein kinase A downstream effector after chronic morphine treatment. Front Pharmacol 5:148.

Beier KT, Steinberg EE, DeLoach KE, Xie S, Miyamichi K, Schwarz L, Gao XJ, Kremer EJ, Malenka RC, Luo L (2015) Circuit architecture of VTA dopamine neurons revealed by systematic input-output mapping. Cell 162: $622-634$.

Bergen AW, Kokoszka J, Peterson R, Long JC, Virkkunen M, Linnoila M, Goldman D (1997) Mu opioid receptor gene variants: lack of association with alcohol dependence. Mol Psychiatry 2:490-494.

Bettler B, Kaupmann K, Mosbacher J, Gassmann M (2004) Molecular structure and physiological functions of GABA(B) receptors. Physiol Rev 84: 835-867.

Bilbao A, Robinson JE, Heilig M, Malanga CJ, Spanagel R, Sommer WH, Thorsell A (2015) A pharmacogenetic determinant of mu-opioid receptor antagonist effects on alcohol reward and consumption: evidence from humanized mice. Biol Psychiatry 77:850-858.

Bonci A, Malenka RC (1999) Properties and plasticity of excitatory synapses on dopaminergic and GABAergic cells in the ventral tegmental area. J Neurosci 19:3723-3730.

Bonci A, Williams JT (1997) Increased probability of GABA release during withdrawal from morphine. J Neurosci 17:796-803.

Bond C, LaForge KS, Tian M, Melia D, Zhang S, Borg L, Gong J, Schluger J, Strong JA, Leal SM, Tischfield JA, Kreek MJ, Yu L (1998) Singlenucleotide polymorphism in the human mu opioid receptor gene alters beta-endorphin binding and activity: possible implications for opiate addiction. Proc Natl Acad Sci U S A 95:9608-9613.

Briand LA, Hilario M, Dow HC, Brodkin ES, Blendy JA, Berton O (2015) Mouse model of OPRM1 (A118G) polymorphism increases sociability and dominance and confers resilience to social defeat. J Neurosci 35: 3582-3590.

Browne CA, Erickson RL, Blendy JA, Lucki I (2017) Genetic variation in the behavioral effects of buprenorphine in female mice derived from a mu- 
rine model of the OPRM1 A118G polymorphism. Neuropharmacology 117:401-407.

Cameron DL, Williams JT (1993) Dopamine D1 receptors facilitate transmitter release. Nature 366:344-347.

Chen M, Zhao Y, Yang H, Luan W, Song J, Cui D, Dong Y, Lai B, Ma L, Zheng P (2015) Morphine disinhibits glutamatergic input to VTA dopamine neurons and promotes dopamine neuron excitation. Elife 4:e09275.

Chieng B, Azriel Y, Mohammadi S, Christie MJ (2011) Distinct cellular properties of identified dopaminergic and GABAergic neurons in the mouse ventral tegmental area. J Physiol 589:3775-3787.

Devine DP, Wise RA (1994) Self-administration of morphine, DAMGO, and DPDPE into the ventral tegmental area of rats. J Neurosci 14: $1978-1984$.

Devine DP, Leone P, Wise RA (1993) Mesolimbic dopamine neurotransmission is increased by administration of mu-opioid receptor antagonists. Eur J Pharmacol 243:55-64.

Di Chiara G, Imperato A (1988) Drugs abused by humans preferentially increase synaptic dopamine concentrations in the mesolimbic system of freely moving rats. Proc Natl Acad Sci U S A 85:5274-5278.

Ducci F, Goldman D (2012) The genetic basis of addictive disorders. Psychiatr Clin North Am 35:495-519.

Edwards NJ, Tejeda HA, Pignatelli M, Zhang S, McDevitt RA, Wu J, Bass CE, Bettler B, Morales M, Bonci A (2017) Circuit specificity in the inhibitory architecture of the VTA regulates cocaine-induced behavior. Nat Neurosci 20:438-448.

Ehlers CL, Lind PA, Wilhelmsen KC (2008) Association between single nucleotide polymorphisms in the mu opioid receptor gene (OPRM1) and self-reported responses to alcohol in American Indians. BMC Med Genet 9:35.

Enoch MA (2013) Genetic influences on the development of alcoholism. Curr Psychiatry Rep 15:412.

Fyfe LW, Cleary DR, Macey TA, Morgan MM, Ingram SL (2010) Tolerance to the antinociceptive effect of morphine in the absence of short-term presynaptic desensitization in rat periaqueductal gray neurons. J Pharmacol Exp Ther 335:674-680.

Gelernter J, Kranzler H, Cubells J (1999) Genetics of two mu opioid receptor gene (OPRM1) exon I polymorphisms: population studies, and allele frequencies in alcohol- and drug-dependent subjects. Mol Psychiatry 4:476-483.

Huang P, Chen C, Mague SD, Blendy JA, Liu-Chen LY (2012) A common single nucleotide polymorphism A118G of the mu opioid receptor alters its N-glycosylation and protein stability. Biochem J 441:379-386.

Johnson SW, North RA (1992) Opioids excite dopamine neurons by hyperpolarization of local interneurons. J Neurosci 12:483-488.

Kanaji N, Basma H, Nelson A, Farid M, Sato T, Nakanishi M, Wang X, Michalski J, Li Y, Gunji Y, Feghali-Bostwick C, Liu X, Rennard SI (2014) Fibroblasts that resist cigarette smoke-induced senescence acquire profibrotic phenotypes. Am J Physiol Lung Cell Mol Physiol 307:L364-L373.

Kauer JA, Malenka RC (2007) Synaptic plasticity and addiction. Nat Rev Neurosci 8:844-858.

Koller G, Zill P, Rujescu D, Ridinger M, Pogarell O, Fehr C, Wodarz N, Bondy B, Soyka M, Preuss UW (2012) Possible association between OPRM1 genetic variance at the 118 locus and alcohol dependence in a large treatment sample: relationship to alcohol dependence symptoms. Alcohol Clin Exp Res 36:1230-1236.

Lammel S, Ion DI, Roeper J, Malenka RC (2011) Projection-specific modulation of dopamine neuron synapses by aversive and rewarding stimuli. Neuron 70:855-862.

Lötsch J, Geisslinger G (2005) Are mu-opioid receptor polymorphisms important for clinical opioid therapy? Trends Mol Med 11:82-89.

Lowe JD, Bailey CP (2015) Functional selectivity and time dependence of mu-opioid receptor desensitization at nerve terminals in the mouse ventral tegmental area. Br J Pharmacol 172:469-481.

Mague SD, Blendy JA (2010) OPRM1 SNP (A118G): involvement in disease development, treatment response, and animal models. Drug Alcohol Depend 108:172-182.

Mague SD, Isiegas C, Huang P, Liu-Chen LY, Lerman C, Blendy JA (2009)
Mouse model of OPRM1 (A118G) polymorphism has sex-specific effects on drug-mediated behavior. Proc Natl Acad Sci U S A 106:10847-10852.

Margolis EB, Hjelmstad GO, Fujita W, Fields HL (2014) Direct bidirectional mu-opioid control of midbrain dopamine neurons. J Neurosci 34:1470714716.

Matsui A, Jarvie BC, Robinson BG, Hentges ST, Williams JT (2014) Separate GABA afferents to dopamine neurons mediate acute action of opioids, development of tolerance, and expression of withdrawal. Neuron 82:1346-1356.

Miranda R, Ray L, Justus A, Meyerson LA, Knopik VS, McGeary J, Monti PM (2010) Initial evidence of an association between OPRM1 and adolescent alcohol misuse. Alcohol Clin Exp Res 34:112-122.

Nestler EJ (2005) Is there a common molecular pathway for addiction? Nat Neurosci 8:1445-1449.

Pennock RL, Hentges ST (2011) Differential expression and sensitivity of presynaptic and postsynaptic opioid receptors regulating hypothalamic proopiomelanocortin neurons. J Neurosci 31:281-288.

Pentney RJ, Gratton A (1991) Effects of local $\delta$ and $\mu$ opioid receptor activation on basal and stimulated dopamine release in striatum and nucleus accumbens of rat: an in vivo electrochemical study. Neuroscience 45:95102.

Prytkova I, Goate A, Hart RP, Slesinger PA (2018) Genetics of alcohol use disorder: a role for induced pluripotent stem cells? Alcohol Clin Exp Res 42:1572-1590.

Ramchandani VA, Umhau J, Pavon FJ, Ruiz-Velasco V, Margas W, Sun H, Damadzic R, Eskay R, Schoor M, Thorsell A, Schwandt ML, Sommer WH, George DT, Parsons LH, Herscovitch P, Hommer D, Heilig M (2011) A genetic determinant of the striatal dopamine response to alcohol in men. Mol Psychiatry 16:809-817.

Ray LA, Hutchison KE (2004) A polymorphism of the mu-opioid receptor gene (OPRM1) and sensitivity to the effects of alcohol in humans. Alcohol Clin Exp Res 28:1789-1795.

Robinson JE, Vardy E, DiBerto JF, Chefer VI, White KL, Fish EW, Chen M, Gigante E, Krouse MC, Sun H, Thorsell A, Roth BL, Heilig M, Malanga CJ (2015) Receptor reserve moderates mesolimbic responses to opioids in a humanized mouse model of the OPRM1 A118G polymorphism. Neuropsychopharmacology 40:2614-2622.

Root DH, Mejias-Aponte CA, Zhang S, Wang HL, Hoffman AF, Lupica CR, Morales M (2014) Single rodent mesohabenular axons release glutamate and GABA. Nat Neurosci 17:1543-1551.

Scarnati MS, Halikere A, Pang ZP (2019) Using human stem cells as a model system to understand the neural mechanisms of alcohol use disorders: current status and outlook. Alcohol 74:83-93.

Schuller AG, King MA, Zhang J, Bolan E, Pan YX, Morgan DJ, Chang A, Czick ME, Unterwald EM, Pasternak GW, Pintar JE (1999) Retention of heroin and morphine- 6 beta-glucuronide analgesia in a new line of mice lacking exon 1 of MOR-1. Nat Neurosci 2:151-156.

Sloan ME, Klepp TD, Gowin JL, Swan JE, Sun H, Stangl BL, Ramchandani VA (2018) The OPRM1 A118G polymorphism: converging evidence against associations with alcohol sensitivity and consumption. Neuropsychopharmacology 43:1530-1538.

Tan EC, Tan CH, Karupathivan U, Yap EP (2003) Mu opioid receptor gene polymorphisms and heroin dependence in Asian populations. Neuroreport 14:569-572.

Wang YJ, Huang P, Ung A, Blendy JA, Liu-Chen LY (2012) Reduced expression of the mu opioid receptor in some, but not all, brain regions in mice with OPRM1 A112G. Neuroscience 205:178-184.

Watabe-Uchida M, Zhu L, Ogawa SK, Vamanrao A, Uchida N (2012) Whole-brain mapping of direct inputs to midbrain dopamine neurons. Neuron 74:858-873.

Zhang Y, Picetti R, Butelman ER, Ho A, Blendy JA, Kreek MJ (2015) Mouse model of the OPRM1 (A118G) polymorphism: differential heroin selfadministration behavior compared with wild-type mice. Neuropsychopharmacology 40:1091-1100.

Zhuang X, Masson J, Gingrich JA, Rayport S, Hen R (2005) Targeted gene expression in dopamine and serotonin neurons of the mouse brain. J Neurosci Methods 143:27-32. 